\title{
International Olympic Committee Consensus Statement
}

\section{Methods for Recording and Reporting of Epidemiological Data on Injury and IIIness in Sports 2020 (Including the STROBE Extension for Sports Injury and IIIness Surveillance (STROBE-SIIS))}

\author{
International Olympic Committee Injury and Illness Epidemiology Consensus Group* ${ }^{\star \dagger}$
}

\begin{abstract}
Background: Injury and illness surveillance, and epidemiological studies, are fundamental elements of concerted efforts to protect the health of the athlete. To encourage consistency in the definitions and methodology used, and to enable data across studies to be compared, research groups have published 11 sport- or setting-specific consensus statements on sports injury (and, eventually, illnesses) epidemiology to date.

Objective: To further strengthen consistency in data collection, injury definitions, and research reporting through an updated set of recommendations for sports injury and illness studies, including a new Strengthening the Reporting of Observational Studies in Epidemiology (STROBE) checklist extension.
\end{abstract}

Study Design: Consensus statement of the International Olympic Committee (IOC).

Methods: The IOC invited a working group of international experts to review relevant literature and provide recommendations. The procedure included an open online survey, several stages of text drafting and consultation by working groups, and a 3-day consensus meeting in October 2019.

Results: This statement includes recommendations for data collection and research reporting covering key components: defining and classifying health problems, severity of health problems, capturing and reporting athlete exposure, expressing risk, burden of health problems, study population characteristics, and data collection methods. Based on these, we also developed a new reporting guideline as a STROBE extension-the STROBE Sports Injury and IIIness Surveillance (STROBE-SIIS).

Conclusion: The IOC encourages ongoing in- and out-of-competition surveillance programs and studies to describe injury and illness trends and patterns, understand their causes, and develop measures to protect the health of the athlete. The implementation of the methods outlined in this statement will advance consistency in data collection and research reporting.

Keywords: injuries; illness; epidemiologic methods; surveillance; STROBE

Injury and illness surveillance, and epidemiological studies, are fundamental elements of concerted efforts to protect the health of the athlete. Carefully designed injury surveillance programs, accurate data capture, and careful analysis of data are building blocks for sports injury/illness prevention programs. Important questions that sports injury and illness surveillance projects are designed to address include: What is the risk of an individual athlete sustaining an acute injury, developing an overuse injury, or becoming ill in a given sport? Within a given sport, what is the typical pattern and severity of

The Orthopaedic Journal of Sports Medicine, 8(2), 2325967120902908 DOI: $10.1177 / 2325967120902908$

(C) The Author(s) 2020 injuries and illnesses? How do injury rates in various sports compare? Do participant characteristics and factors within competition and training affect the risk?

To encourage consistency in the definitions and methods used, and to enable data across studies to be compared, research teams have published 11 consensus papers on sports injury (and, eventually, illness) epidemiology. Most of them addressed specific sports—cricket, ${ }^{84}$ football, ${ }^{50}$ rugby union, ${ }^{52}$ rugby league, ${ }^{65}$ aquatic sports, ${ }^{78}$ tennis, ${ }^{86}$ athletics, ${ }^{98}$ and horse racing. ${ }^{102}$ Two statements covered multisport events ${ }^{64}$ and mass-participation events (eg, marathon races). ${ }^{92}$

We now have more than a decade of experience with the existing recommendations. Sports epidemiology has advanced, with a new focus on overuse injuries and also

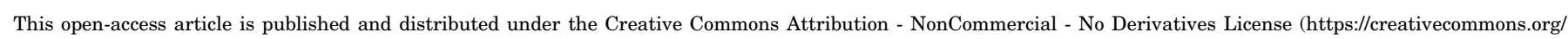

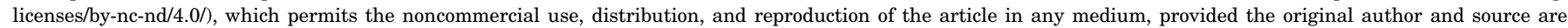

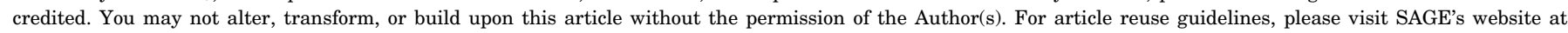
http://www.sagepub.com/journals-permissions. 
on illnesses. Data collection and reporting methods have also advanced as data are being collected for routine surveillance or predefined observational or intervention studies in diverse settings, ranging from community to elite sports, from youth sports to the master's level, in ablebodied and athletes with disabilities, and in team sports and individual sports. In 2005, when the first of these sports injury surveillance consensus statements was developed, there were no agreed on research reporting methods (eg, the EQUATOR Network [Enhancing the QUAlity and Transparency Of health Research] was just holding its inaugural meeting). Many important research epidemiological issues were not discussed in any of the previous sportsrelated consensus statements.

In 2019, the International Olympic Committee (IOC) convened an expert panel to update recommendations for the field of sports epidemiology - this consensus statement. We drew on recent methods developments and the experience of scientists working in the field of sports injury and illness surveillance. A specific goal was to further encourage consistency in data collection, injury definitions, and research reporting (in line, where possible, with the EQUATOR Network recommendations). Our aim was to provide hands-on guidance to researchers on how to plan and conduct data collection and how to report data. We anticipate that this sports-generic statement will be complemented by subsequent sport-specific statements with more detailed recommendations relevant for the sports and/or setting. We also extended the Strengthening the Reporting of Observational Studies in Epidemiology (STROBE) checklist ${ }^{63}$ - the STROBE Sports Injury and Illness Surveillance (STROBE-SIIS) - to assist users in planning surveillance studies and in writing articles based on injury/illness data.

\section{METHODS}

This was an 8-stage process: (1) an online survey; (2) working groups reviewed the survey responses, available literature, and drafted text; (3) all consensus group members reviewed the draft text; (4) the initial working groups revised their draft text; (5) a 3-day consensus meeting was held in Lausanne, Switzerland (October 9-11, 2019); (6) new working groups revised the draft text; (7) an editorial group (R.B., K.C., B.R., K.M.K.) made final edits; and (8) all authors reviewed and approved the final draft.

The IOC Medical and Scientific Department appointed R.B. to chair the consensus group. He selected a consensus group that included at least 1 author from previous consensus statements on sports injury epidemiology. Care was taken to include experts with research experience from diverse settings (sports types, age groups, performance levels) and with a variety of health problems as outcomes (eg, illnesses, not only acute injuries).

1. Online survey: The survey included 25 questions inviting free-text comments on aspects identified from previous consensus statements. The survey link was open to the public and was launched via email and Twitter on February 1, 2019, and closed on March 15, 2019. We received comments from 188 respondents, including 19 consensus group members. A report including all responses was distributed to the consensus group on August 31, 2019.

2. The consensus group was split into 7 working groups. Each working group was responsible for a subset of the sections presented in this final document (eg, "classifying health problems"). For each section, the group reviewed the survey responses, examined available relevant literature (including previous consensus statements), and composed draft text with the necessary background and proposed definitions and recommendations.

3. R.B. created a complete draft that was shared online with the consensus group, asking all members to provide written comments/suggestions. Comments were made online and were visible to all group members.

4. The working groups revised their sections based on input from other members of the consensus group.

5. At the in-person consensus meeting, attended by all consensus group members, the revised draft was discussed section by section, focusing on recommendations and definitions.

6. Seven new revision groups made up of those not responsible for drafting the original section under discussion were responsible for taking notes and revising the text. If necessary, items were voted on to achieve a majority.

7. The revised draft was edited for consistency and form by R.B. and reviewed with the rest of the editorial group (K.C., B.R., K.M.K.).

8. Finally, the manuscript was distributed to the consensus group members for final approval.

\section{DEFINING AND CLASSIFYING HEALTH PROBLEMS}

\section{Terminology for Health Problems}

The World Health Organization (WHO) defines health as "a state of complete physical, mental, and social well-being" and not merely the absence of a disease or infirmity. ${ }^{114}$ Extending this definition, Clarsen et $\mathrm{al}^{15}$ defined an

\footnotetext{
*Address correspondence to Roald Bahr, MD, PhD, Department of Sports Medicine, Oslo Sports Trauma Research Center, Norwegian School of Sport Sciences, PB 4014 Ullevål Stadion, 0806 Oslo, Norway (email: roald@nih.no).

${ }^{\dagger}$ All authors are listed in the Authors section at the end of this article.

This article has been co-published in the British Journal of Sports Medicine. Minor differences exist between the 2 versions to be consistent with OJSM editorial style.

Final revision submitted December 30, 2019; accepted January 3, 2020.

One or more of the authors has declared the following potential conflict of interest or source of funding: B.R. receives payment for duties as Editor-in-

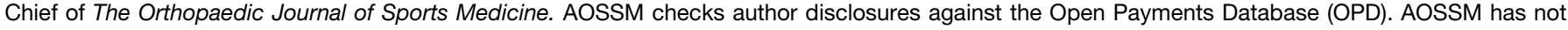
conducted an independent investigation on the OPD and disclaims any liability or responsibility relating thereto.
} 


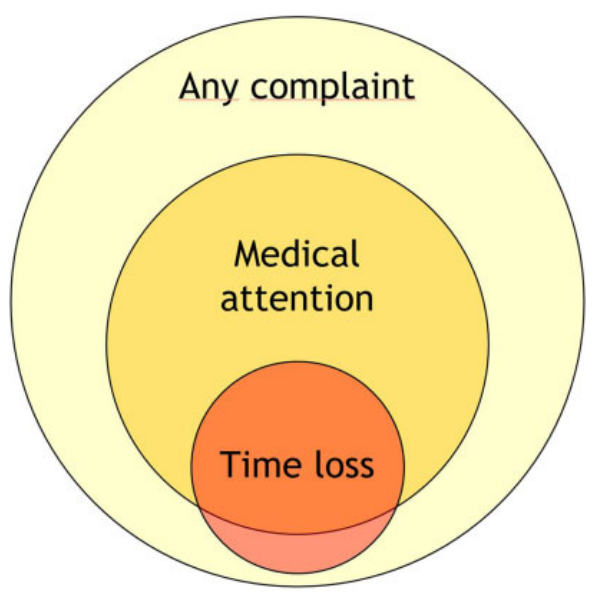

Figure 1. Distribution of health problems by consequences (not to scale). Adapted from Clarsen and Bahr. ${ }^{14}$

athletic health problem as any condition that reduces an athlete's normal state of full health, irrespective of its consequences on the athlete's sports participation or performance or whether the athlete sought medical attention. This constitutes an umbrella term that includes, but is not limited to, injury and illness.

Health problems can have several consequences. A health problem that results in an athlete receiving medical attention is referred to as a "medical attention" health problem, and a health problem that results in a player being unable to complete the current or future training session or competition is referred to as a "time-loss" health problem. ${ }^{51,52,65,78,84,98}$ As not all health problems limit an athlete's ability to participate nor require medical attention, broader definitions (self-reported, symptom-based, or performance based) will capture more health problems. Figure 1 illustrates these differences.

\section{Defining Injury and IIIness}

Previous consensus statements on injury and illness in sports have proposed largely consistent definitions for an injury and illness. ${ }^{\ddagger}$ Differences in definition stem from the specific sport or context for which statements were developed. For this consensus statement, we define an injury and illness as follows:

- Injury is tissue damage or other derangement of normal physical function due to participation in sports, resulting from rapid or repetitive transfer of kinetic energy.

- Illness is a complaint or disorder experienced by an athlete, not related to the injury. Illnesses include healthrelated problems in physical (eg, influenza), mental (eg, depression), or social well-being or removal or loss of vital elements (air, water, warmth).

We acknowledge that there is not always a clear distinction between injury and illness. The consensus was that for

${ }^{\ddagger}$ References 51, 52, 64, 78, 83, 84, 86, 92, 98, 102. injury, the primary mode involves the transfer of kinetic energy, but other types of injury, such as sunburn or drowning, may have a different etiology.

These definitions are meant to be inclusive; they embrace a broad array of injury- and illness-related health problems that may affect an athlete. Depending on the goal of the monitoring activity, data recording may be limited to specific health problems that constitute a narrower subset of the above definitions (ie, via an operational definition). If the surveillance program has a narrow scope (eg, to capture only concussions in school rugby), data recording can be limited to the specific injury type of interest.

\section{Relationship to Sports Activity}

Health problems may result:

1. Directly from participation in competition or from training in the fundamental skills of a sport (eg, players colliding in a match, overuse from repetitive training, or transmission of a skin infection from contact with another player).

2. Indirectly from participation in activities related to competition or training in a sport but not during competition or a training session (eg, slipping, falling, and sustaining an injury when in the Olympic village; developing an illness after international travel to a competition or an illness deemed to be related to an increased training load over a few weeks).

3. From activities that are not at all related to participation in sports, that is, would occur in the absence of participation during competition or training in the fundamental skills of a sport (eg, car crash, sudden cardiac arrest at home).

Depending on the purposes of the study, researchers may want to report health problems in these categories separately.

\section{Mode of Onset}

Traditionally, health problems have been classified into those that have a sudden onset and those that have a gradual onset. Sudden-onset health problems were considered to be those that resulted from a specific identifiable event (eg, a collision between an athlete and an object causing a fracture). Gradual-onset health problems, on the other hand, were considered to be those that lack a definable sudden, precipitating event as the onset (eg, a tendinopathy induced by repetitive movement).

The term "overuse injury" is commonly applied to gradual-onset injuries. However, this term is used inconsistently in the literature, ${ }^{80,90}$ and most injury surveillance systems do not define "overuse injury."90

Health problems may have elements of both sudden onset and gradual onset. For example, a long-distance runner with an intensive training regimen may have insufficient recovery, resulting in cumulative stress-related changes to the bone, but presenting as an acute tibial fracture without prior pain. The dichotomy between sudden and gradual onset, which most methods of data capture are 
based on, means such important nuances may be missed. One option to address this problem would be to classify health problems based on the underlying pathology, whether this indicates a single or repetitive pathogenic mechanism, based on imaging studies (eg, magnetic resonance imaging, ultrasound) or tissue biopsies. However, routine capture of such detail in a reliable manner within a surveillance system is challenging.

\section{Mode of Onset-Injury}

For injuries, classic epidemiology provides a solution for this issue by viewing health problems as the result of a series of interactions between agent, host, and environment. ${ }^{45,58}$ Injury epidemiology adapted this model by defining kinetic energy as the "agent" of injury. ${ }^{56,69,107}$

In this paradigm, following the definition above, injury results from a transfer of kinetic energy (agent) that damages tissue. Injury may result from a nearinstantaneous exchange of large quantities of kinetic energy (eg, as in a collision between athletes), from the gradual accumulation of low-energy transfer over time (as in the bone stress injury example), or from a combination of both mechanisms (repetitive training regimen resulting in tendon weakness that then manifests itself acutely as a tear from acceleration forces applied during a single jump). This model suggests mode of onset for injuries should be conceptualized as a continuum interplay of energy exposures.

\section{Mode of Onset-IIIness}

Illnesses, like injuries, may be either associated with a specific precipitating event (eg, a player ingesting a toxin from food and suffering gastrointestinal illness that manifests within hours of exposure) or may involve a progressive pathway that cannot be linked to a specific precipitating event (eg, progressive fatigue from increased training load). Similarly, the time scale for sudden-onset illness can be seconds or minutes (eg, acute anaphylaxis), develop within hours after exposure to a pathogen or toxin (eg, gastroenteritis), or even days or weeks (eg, upper respiratory tract infection).

The mode of onset for illnesses may also be related to a specific event, with or without some underlying subclinical pathology. For example, myalgic encephalomyelitis will typically present without a precipitating event, whereas influenza usually has a point source of exposure (although this may be difficult to trace). As with injuries, many illnesses reflect both the underlying pathology and a suddenonset event (eg, an athlete may be predisposed to bronchial hyperreactivity, and this may present acutely as bronchoconstriction when exposed to air pollution at a venue).

\section{Classifying the Mode of Onset}

We recommend that injury/illness surveillance discontinue use of sudden onset and gradual onset as a simple dichotomy and implement methods that capture relevant subtleties. We encourage researchers to develop and use measures that will help identify injuries and illnesses that involve mixed
TABLE 1

Examples: Assessment of Mode of Onset

\begin{tabular}{|c|c|c|}
\hline Mechanism & Presentation & Example \\
\hline Acute & $\begin{array}{r}\text { Sudden } \\
\text { onset }\end{array}$ & $\begin{array}{l}\text { 1. A sprinter pulls up suddenly in a } \\
\text { race, stops, and hobbles a few steps } \\
\text { in obvious pain with a hamstring } \\
\text { injury. }\end{array}$ \\
\hline Repetitive & $\begin{array}{r}\text { Sudden } \\
\text { onset }\end{array}$ & $\begin{array}{l}\text { 2. A gymnast experiences a frank tibial } \\
\text { and fibular fracture on landing from } \\
\text { a vault; computed tomography } \\
\text { imaging reveals pre-existing } \\
\text { morphological changes consistent } \\
\text { with bone stress, that is, a stress } \\
\text { fracture. }\end{array}$ \\
\hline Repetitive & $\begin{array}{c}\text { Gradual } \\
\text { onset }\end{array}$ & $\begin{array}{l}\text { 3. A swimmer experiences a gradual } \\
\text { increase in shoulder pain over the } \\
\text { course of a season; diagnosed as } \\
\text { rotator cuff tendinopathy on } \\
\text { magnetic resonance imaging. }\end{array}$ \\
\hline
\end{tabular}

acute and repetitive mechanisms. Data collectors should consider whether a health problem results from a clear acute mechanism, clear repetitive mechanism, or appears to include a mix of both elements (Table 1). Examples 1 and 3 in Table 1 reflect clear acute and repetitive etiology, respectively, whereas example 2 represents a mixed etiology.

\section{Classifying the Mechanism of Injury}

Mechanism of onset has typically been defined only in the context of sudden-onset injuries. Sudden-onset health problems can result from contact and noncontact mechanisms; this classification is discussed below and presented in Table 2 .

Direct contact mechanisms directly lead to the health problem in an immediate and proximal manner. Indirect contact mechanisms also stem from contact with other athletes or an object. The force is not applied directly to the injured area but contributes to the causal chain, leading to the health problem. ${ }^{13,20,57,82}$ Noncontact mechanisms are those that lead to health problems without any direct or indirect contact from another external source. Gradualonset injuries, by their nature, are noncontact.

We anticipate that subsequent sport-specific consensus statements will provide more detailed subclassifications to address specific features of contact mechanisms (eg, subclassification of contact with objects, such as ball, bat, net, gate). Future sport-specific statements may also give specific recommendations on other categories for classification related to injury causation (eg, rule infringements, particular movements, or other sport-specific features). The International Classification of Diseases (ICD) External Causes chapter $^{111}$ and the International Classification of External Causes of Injury ${ }^{112}$ provide specific codes that might be useful.

\section{Multiple Events and Health Problems}

One of the particular features of sports epidemiology, compared with other settings, is the relatively high chance that 
TABLE 2

Examples: Classification of Contact as a Mechanism for Sudden-Onset Injuries ${ }^{a}$

\begin{tabular}{|c|c|c|}
\hline Injury & Type of Contact & Example \\
\hline \multicolumn{3}{|l|}{ Noncontact } \\
\hline None & $\begin{array}{l}\text { No evidence of disruption } \\
\text { or perturbation of the } \\
\text { player's movement } \\
\text { pattern }\end{array}$ & $\begin{array}{l}\text { ACL tear in a basketball } \\
\text { player landing with } \\
\text { knee valgus/rotation } \\
\text { after a jump, with no } \\
\text { contact with other } \\
\text { players }\end{array}$ \\
\hline \multicolumn{3}{|l|}{ Contact } \\
\hline Indirect & Through another athlete & $\begin{array}{l}\text { ACL tear in a handball } \\
\text { player landing out of } \\
\text { balance after being } \\
\text { pushed on her shoulder } \\
\text { by an opponent while } \\
\text { in the air }\end{array}$ \\
\hline Indirect & Through an object & $\begin{array}{l}\text { Downhill skier suffers a } \\
\text { concussion from a } \\
\text { crash after being } \\
\text { knocked off balance, } \\
\text { hitting the gate with } \\
\text { his knee }\end{array}$ \\
\hline \multicolumn{3}{|l|}{ Contact } \\
\hline Direct & With another athlete & $\begin{array}{l}\text { ACL tear in a football } \\
\text { player from a direct } \\
\text { tackle to the anterior } \\
\text { aspect of the knee, } \\
\text { forcing the knee into } \\
\text { hyperextension }\end{array}$ \\
\hline Direct & With an object & $\begin{array}{l}\text { Volleyball player being } \\
\text { hit in the face by a } \\
\text { spiked ball, resulting } \\
\text { in a concussion }\end{array}$ \\
\hline
\end{tabular}

${ }^{a} \mathrm{ACL}$, anterior cruciate ligament. an athlete will sustain more than 1 health problem over the follow-up period. This is illustrated in Figure 2.

The relatively common occurrence of multiple health problems in a single patient poses challenges for the reporting and analysis of sports injury and illness data. ${ }^{44}$ In particular, note that the number of athletes in a study is unlikely to be the same as the number of reported health conditions, and both should be stated. When reporting the frequency (or proportion) of specific diagnoses or other characteristics, it is important to state clearly whether this is expressed as the proportion of all athletes followed up, the proportion of all injured athletes, or the proportion of all reported injuries.

\section{Subsequent, Recurrent, and/or Exacerbation of Health Problems}

Was a subsequent health problem related to previous health problems? This is an important question in the field. To know whether health problems follow previous health problems requires both sets of problems to be classified correctly using consistent terminology. This exercise can provide greater insight into the etiological factors that underpin subsequent health problems. ${ }^{34}$

Hamilton et $\mathrm{al}^{60}$ provided a useful framework to categorize subsequent injuries/illnesses and exacerbations in sport (Figure 3). More recent frameworks incorporate extensive criteria ${ }^{34,100,101}$ that require judgment by trained clinicians, which may be beyond the scope and capacity of many surveillance protocols. When reporting frameworks become more complex, there is a greater risk for data errors. ${ }^{93}$ In general, we do not recommend complex frameworks but they can be considered for sophisticated data collection and analysis where appropriate expertise and resources exist.

The recommended subsequent injury terminology, adapted from Hamilton et al, ${ }^{60}$ includes noting whether

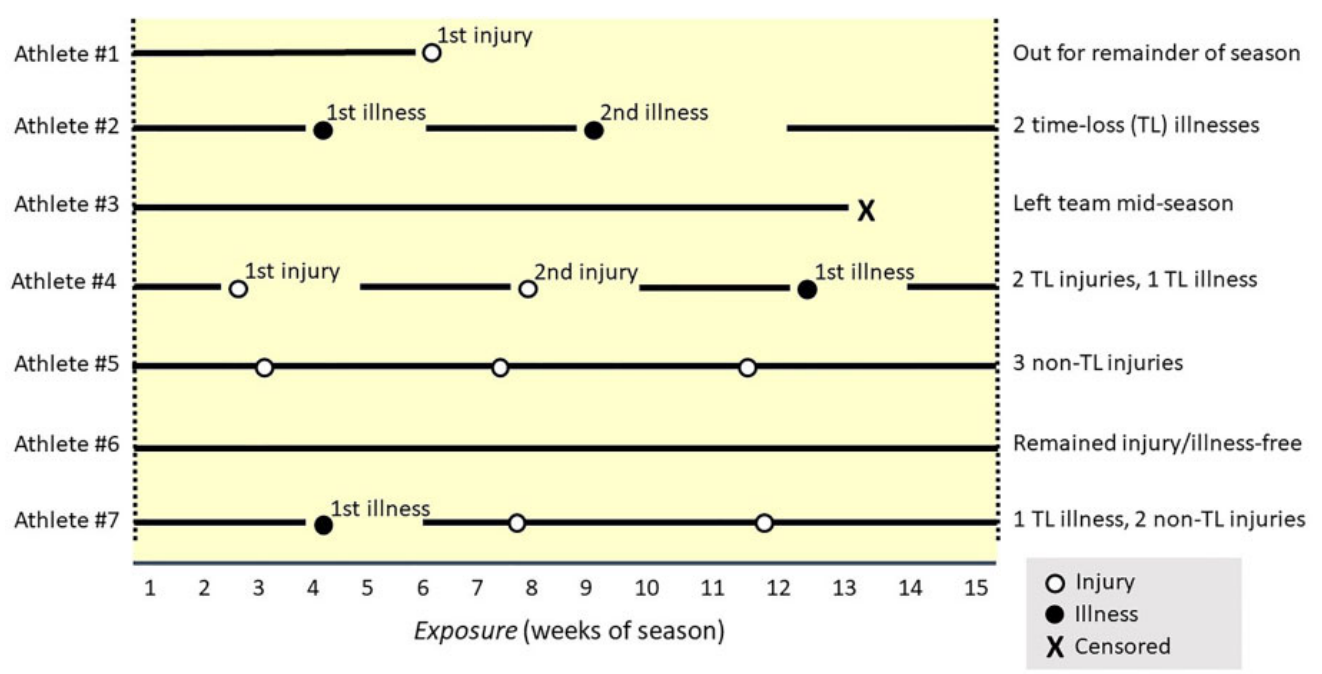

Figure 2. Examples of hypothetical prospectively collected injury/illness data (adapted from Finch and Marshall ${ }^{37}$ ). " $X$ " indicates when a period of surveillance is ended because the athlete left, unrelated to health problems, before the end of the study period; this is called censoring. 


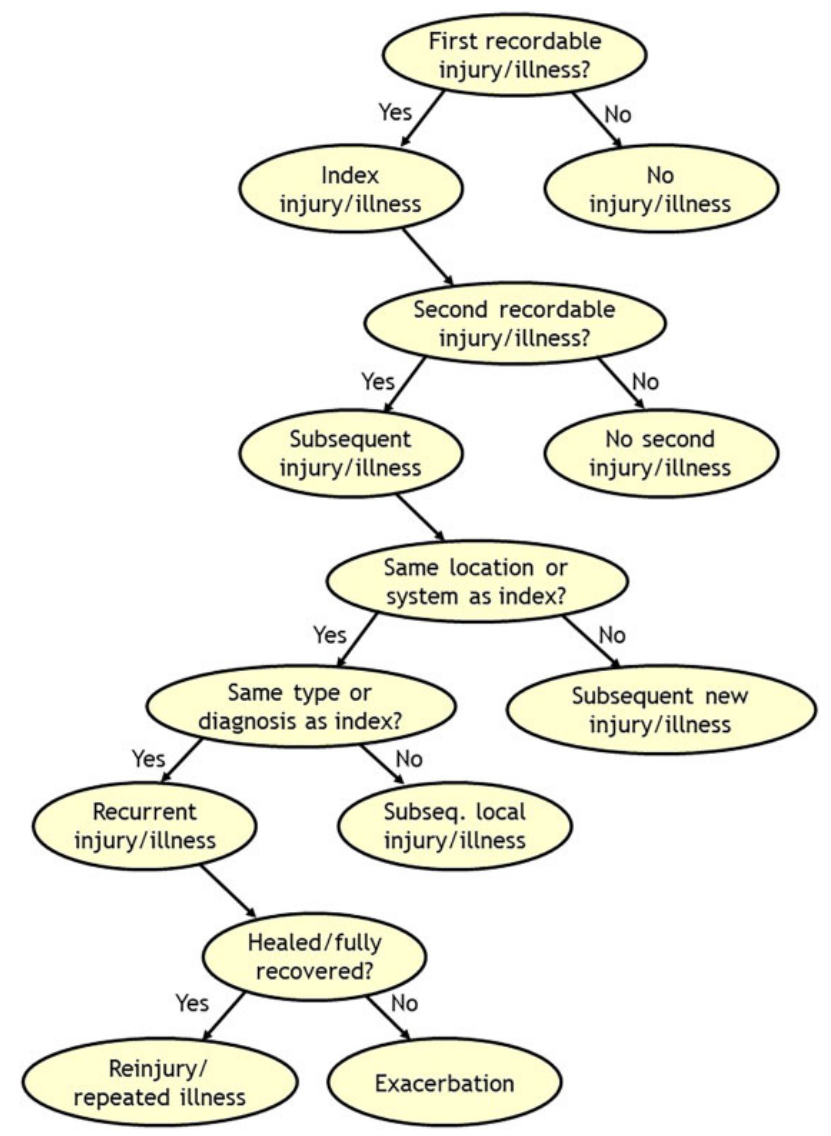

Figure 3. Classification tree for subsequent health problems (adapted from Hamilton et $\mathrm{al}^{60}$ ). Definitions: (1) index injury (illness) is the first recorded injury (illness), and (2) subsequent injury (illness) is any injury (illness) occurring after the index injury (illness): (a) subsequent injury to a different location than the index injury (subsequent illness involving a different system than the index illness), (b) subsequent injury to the same location but of a different tissue type than the index injury (subsequent illness involving the same system but of a different type/other diagnosis), or (c) subsequent recurrent injury (illness) is a subsequent injury to the same site and of the same type as the index injury (subsequent illness involving the same system and type as the index illness). Third, fourth, or more health problems should be assessed relative to the initial index health problem and all other previous ones (eg, second and third health problems).

subsequent injuries (1) affect the same site but other tissues (eg, knee but meniscus instead of anterior cruciate ligament [ACL] alone) or (2) affect other sites. Subsequent illness terminology ${ }^{60}$ notes whether the subsequent illnesses is the same system (eg, respiratory) but other diagnosis (eg, bronchospasm as distinct from a viral illness) or to other systems. The relevant definitions are shown in Figure 3. Note that an injury may be subsequent to an illness and vice versa (eg, bone stress injury following diagnosis of an eating disorder, depression following a lengthy recovery from revision ACL reconstruction).
Subsequent injuries to the same location and tissue as the index injury are recurrences if the index injury was healed/fully recovered or exacerbations if the index injury was not yet healed/fully recovered. Subsequent illnesses to the same system and type as the index illness are recurrences if the individual has fully recovered from the index illness and exacerbations if the patient has not yet recovered from the index illness. Healed/fully recovered from injury (or illness) is defined as when the athlete is fully available for training and competition (see "Severity of Health Problems" section).

To illustrate how to classify a subsequent injury, consider athlete "A" who, following an ACL rupture and surgical reconstruction, presents late in the rehabilitation period before returning to play with swelling and pain in the knee after a slip and fall injury, resulting in a graft tear. This injury would be classified as an exacerbation of the index injury. In contrast, athlete " $B$ " rehabilitated successfully after ACL reconstruction and returned to play; that player presents with pain and swelling in the same knee. If the diagnosis is a torn ACL graft, this would be classified as a recurrent injury. If the diagnosis is a meniscal tear (ACL graft intact), this is a local subsequent injury.

To illustrate how to classify subsequent illness, consider athlete "C" who has withdrawn from sports participation due to an upper respiratory tract infection caused by influenza type A virus, which then progresses to a lower respiratory tract infection, resulting in a diagnosis of viral pneumonia. As athlete " $\mathrm{C}$ " is diagnosed with pneumonia before recovery and return to play, the diagnosis of pneumonia is an exacerbation of a recurrent illness. In contrast, athlete " $\mathrm{D}$," following full recovery from the upper respiratory tract infection and returning to play, is diagnosed with pneumonia; this illness is a subsequent new illness.

Time to recurrence or an exacerbation should be recorded in days (see "Severity of Health Problems" section). A minimum list of data items recommended when collecting information on subsequent injuries or illnesses is shown in Table 3 .

\section{Classifying Sports Injury and IIIness Diagnoses}

Injury and illness classification systems are used in sports medicine to:

- Accurately classify and group diagnoses for research or reporting, allowing easy grouping into parent classifications for summary, so that injury and illness trends can be monitored over time or injury or illness incidence or prevalence can be compared between groups (eg, different teams, leagues, sports, sexes), potentially leading to risk factor and preventive studies.

- Create databases from which cases can be extracted for research on particular or specific types of injuries and illnesses.

In the late $1980 \mathrm{~s}$, clinicians and researchers were using the 9 th edition of the ICD. ${ }^{111}$ The ICD system is an important international standard, yet even the 11th edition, released in 2018, lacks some classifications important in 
sports injury and illness surveillance. Hamstring strain and exercise-associated postural hypotension are 2 examples. ${ }^{1,27,88}$ We encourage developers to include more sports medicine diagnoses in future revisions of the ICD.

In the early 1990s, in Canada and Australia, 2 alternate diagnostic coding systems were developed specifically for sports medicine, and these have flourished into the most widely used systems in sports injury surveillance in the world today. Their "open access" nature has allowed

\section{TABLE 3}

Recommendations for Key Data Items That Should Be

Collected and Reported on in Surveillance Systems

to Enable Multiple and Subsequent Injuries/Illnesses to Be Monitored ${ }^{a}$

Data Item
$\begin{aligned} & \text { Unique identifier to link all } \\ & \text { injuries/illnesses in } 1 \\ & \text { participant }\end{aligned}$

Injury/illness time order sequence

Multiple injury/illness type details

Injury/illness details, including diagnosis

Details of circumstances and time elapsed between
Why It Is Important

All participants require a unique identifier that covers all seasons/time periods and should be anonymized to protect privacy and confidentiality.

The exact date (day, month, year) of the onset of each health problem is essential for the sequence to be clear. For greater precision, time can be important if there are multiple events/heats each day (eg, swimming).

Multiple injuries and illnesses can be the result of different or same events or etiology, coincide at the same time, or a mixture of both. Injuries/ illnesses need to be linked to the specific circumstances/ events that led to them. Date and time stamping, directly linked to diagnoses of all injuries/illnesses, can inform these relationships.

Collect information on the nature, body region/system, tissue/organ, laterality, and diagnosis for all injuries/ illnesses. Sport injury/illness diagnostic classification and coding are optimal.

The time elapsed between injuries/illnesses will be determined by date and time stamping. If away from participation in sport, then it is important to collect details and date/time stamps regarding rest, rehabilitation, treatment, training, modified sport participation, and return to play. other researchers to use them free of charge (with acknowledgment). These diagnostic coding systems are the Sport Medicine Diagnostic Coding System (SMDCS) and the Orchard Sports Injury Classification System (OSICS). Both are based on initial codes to represent the body area and further codes to represent the injury type or pathology.

One advantage of these coding systems is that they are less cumbersome to apply than ICD codes, especially when built into electronic systems with drop-down menus, taking advantage of the body area and tissue/pathology type categories. The full ICD-11 coding system includes 55,000 codes, of which the majority are not relevant in sports medicine, compared with 750 to 1500 codes for versions of the SMDCS and OSICS.

When reporting aggregate injury data, we recommend using the categories for body area (Table 4 ) and tissue type and pathology (Table 5) outlined below. In addition, the categories for organ system/region (Table 7) and etiology (Table 8) are presented below for illnesses.

When recording injuries or illnesses, the diagnosis should be recorded in as much detail as possible given the information available and the expertise of the individual reporting. Acknowledging that some studies will rely on athlete self-reports or proxy reports by parents, coaches, or other nonmedically trained staff, this consensus group also suggests categories to guide reporting of illnesses (Table 9). When injury data are reported by athletes or nonmedical staff, we recommend that reporting is limited to the body area, as their reporting of tissue type and abnormality is unreliable..$^{53}$

To facilitate reporting based on diagnostic codes, a companion paper has been written with a supplemental Excel (Microsoft) data file that provides a full list of revised SMDCS and OSIICS (Orchard Sports Injury and Illness Classification System) codes, along with a translation between both systems and the ICD system. ${ }^{85}$

\section{Injuries-Body Area Categories}

Wherever possible, we tried to define body areas anatomically as either joints or segments. However, we made exceptions based on common clinical presentations in sport where needed. For example, the hip/groin is an area that we have defined, which is a combination of a joint and part of a segment, and therefore not a singular anatomical region.

When 1 injury event results in more than 1 injury, the individual diagnoses should be recorded and classified separately. However, for injury incidence and prevalence reporting purposes, this will be counted as 1 injury, and severity should be reported as the severity of the principal (most severe) injury (see below for further explanations).

\section{Injuries-Tissue- and Pathology-Type Categories}

Using consensus methodology, we compared "injury type" codes from the OSICS and SMDCS to arrive at definitions of injury types. We constructed this table to be a single table reflecting "injury types" (as per the OSICS) but split 2

${ }^{a}$ Modified from Finch and Fortington. ${ }^{35}$ 
TABLE 4

Recommended Categories of Body Regions and Areas for Injuries ${ }^{a}$

\begin{tabular}{|c|c|c|c|}
\hline Body Region/Area & OSIICS & SMDCS & Note \\
\hline \multicolumn{4}{|l|}{ Head and neck } \\
\hline Head & $\mathrm{H}$ & $\mathrm{HE}$ & $\begin{array}{l}\text { Includes face, brain } \\
\text { (concussion), eyes, ears, } \\
\text { teeth }\end{array}$ \\
\hline Neck & $\mathrm{N}$ & $\mathrm{NE}$ & $\begin{array}{l}\text { Includes cervical spine, } \\
\text { larynx, major vessels }\end{array}$ \\
\hline \multicolumn{4}{|l|}{ Upper limb } \\
\hline Shoulder & $\mathrm{S}$ & $\mathrm{SH}$ & $\begin{array}{l}\text { Includes clavicle, scapula, } \\
\text { rotator cuff, biceps } \\
\text { tendon origin }\end{array}$ \\
\hline Upper arm & $\mathrm{U}$ & $\mathrm{AR}$ & \\
\hline Elbow & $\mathrm{E}$ & EL & $\begin{array}{l}\text { Ligaments, insertional } \\
\text { biceps and triceps tendon }\end{array}$ \\
\hline Forearm & $\mathrm{R}$ & FA & $\begin{array}{l}\text { Includes nonarticular } \\
\text { radial and ulnar injuries }\end{array}$ \\
\hline Wrist & W & WR & Carpus \\
\hline Hand & $\mathrm{P}$ & HA & Includes finger, thumb \\
\hline \multicolumn{4}{|l|}{ Trunk } \\
\hline Chest & $\mathrm{C}$ & $\mathrm{CH}$ & $\begin{array}{l}\text { Sternum, ribs, breast, chest } \\
\text { organs }\end{array}$ \\
\hline Thoracic spine & $\mathrm{D}$ & $\mathrm{TS}$ & $\begin{array}{l}\text { Thoracic spine, } \\
\text { costovertebral joints }\end{array}$ \\
\hline Lumbosacral & $\mathrm{L}$ & LS & $\begin{array}{l}\text { Includes lumbar spine, } \\
\text { sacroiliac joints, sacrum, } \\
\text { coccyx, buttocks }\end{array}$ \\
\hline Abdomen & $\mathrm{O}$ & $\mathrm{AB}$ & $\begin{array}{l}\text { Below diaphragm and } \\
\text { above inguinal canal, } \\
\text { includes abdominal organs }\end{array}$ \\
\hline \multicolumn{4}{|l|}{ Lower limb } \\
\hline Hip/groin & $\mathrm{G}$ & $\mathrm{HI}$ & $\begin{array}{l}\text { Hip and anterior } \\
\text { musculoskeletal } \\
\text { structures (eg, pubic } \\
\text { symphysis, proximal } \\
\text { adductors, iliopsoas) }{ }^{108}\end{array}$ \\
\hline Thigh & $\mathrm{T}$ & $\mathrm{TH}$ & $\begin{array}{l}\text { Includes femur, hamstring } \\
\text { (including ischial } \\
\text { tuberosity), quadriceps, } \\
\text { middistal adductors }\end{array}$ \\
\hline Knee & $\mathrm{K}$ & $\mathrm{KN}$ & $\begin{array}{l}\text { Includes patella, patellar } \\
\text { tendon, pes anserinus }\end{array}$ \\
\hline Lower leg & Q & $\mathrm{LE}$ & $\begin{array}{l}\text { Includes nonarticular tibial } \\
\text { and fibular injuries, calf, } \\
\text { Achilles tendon }\end{array}$ \\
\hline Ankle & $\mathrm{A}$ & $\mathrm{AN}$ & $\begin{array}{l}\text { Includes syndesmosis, } \\
\text { talocrural and subtalar } \\
\text { joints }\end{array}$ \\
\hline Foot & $\mathrm{F}$ & FO & $\begin{array}{l}\text { Includes toes, calcaneus, } \\
\text { plantar fascia }\end{array}$ \\
\hline Unspecified & $\mathrm{Z}$ & $\mathrm{OO}$ & \\
\hline $\begin{array}{l}\text { Multiple (single } \\
\text { injury crossing } \\
\geq 2 \text { regions) }\end{array}$ & $\mathrm{X}$ & $\mathrm{OO}$ & \\
\hline
\end{tabular}

${ }^{a}$ OSIICS, Orchard Sports Injury and Illness Classification System; SMDCS, Sport Medicine Diagnostic Coding System.

columns into "tissue" (as the broad area) and then "pathology" type more specifically. This reflects the original approach taken in the SMDCS.

\section{Recommendations: Reporting Injury Characteristics}

Injury characteristics are often reported in a single table by region, injury type, or both. Cross-tabulations depicting data by region and injury type (ie, combining the 2 into 1 table) often become large and unwieldy. It can leave many cells empty or with very few cases (which can then compromise confidentiality) unless the dataset is unusually large. Such tables often also provide insufficient information for research focused on specific areas or sports. For example, in a sport where knee sprains dominate, it may be desirable to report subgroups of these (eg, ACL, medial collateral ligament) in greater detail.

In many cases, a better reporting option is to combine region and type and diagnosis in 1 table, such as in the example shown in Table 6 , where some categories have been collapsed at the level of body region (bold), some regions have been split further into injury types (subheader), and some even at the level of specific diagnosis (italics). It is expected that subsequent consensus statements on specific sports will provide recommendations on suitable, standard formats for each sport to facilitate a direct comparison of data on key injury types from studies on the same sport.

\section{Illness - Categories for Organ System and Etiology}

Illness consensus categories are presented in Tables 7 and 8 . These are more detailed than the original versions of the SMDCS and OSICS. Our tables diverge from the ICD categorization format in which body systems and abnormality types are grouped together. We believe that it is important to recognize that an illness, like an injury, both affects a body system and has a specific pathological type. A respiratory infection does not need to be considered either only as a respiratory condition or an infection; it is certainly both. Our recommended illness systems are similar to many of those in the ICD, but we have merged some systems, such as the upper respiratory system and nose/throat.

The professional background of those who report health data will influence the final data quality (see "Data Collection Methods" section). ${ }^{39}$ When athletes themselves (or nonclinical recorders like coaching staff) are asked to capture illness data, they should be encouraged to record symptoms rather than attempt a diagnosis. Table 9 lists symptom clusters that are characteristic of various systems. We caution that this table requires additional validation and may be modified in the future. Mapping symptoms to body systems sacrifices some accuracy; however, in circumstances where expert recorders are unavailable, it is better to have general systems diagnosis data than no data at all.

\section{Recommendations: Reporting Illness Characteristics}

As was the case when we discussed reporting of injury data, we recommend against illness data being reported as cross-tabulations of organ system by type of etiology type. 
TABLE 5

Recommended Categories of Tissue and Pathology Types for Injuries ${ }^{a}$

\begin{tabular}{|c|c|c|c|}
\hline Tissue/Pathology Type & OSIICS & SMDCS & Note \\
\hline \multicolumn{4}{|l|}{ Muscle/tendon } \\
\hline Muscle injury & M & $10.07-10.09$ & Includes strain, tear, rupture, intramuscular tendon \\
\hline $\begin{array}{l}\text { Muscle compartment } \\
\text { syndrome }\end{array}$ & $\mathrm{Y}$ & 10.36 & \\
\hline Tendinopathy & $\mathrm{T}$ & $10.28-10.29$ & $\begin{array}{l}\text { Includes paratenon, related bursa, fasciopathy, partial tear, tendon } \\
\text { subluxation (all nonrupture), enthesopathy }\end{array}$ \\
\hline \multicolumn{4}{|r|}{ 6 } \\
\hline Brain/spinal cord injury & $\mathrm{N}$ & 20.40 & Includes concussion and all forms of brain injuries and spinal cord \\
\hline Peripheral nerve injury & $\mathrm{N}$ & $20.39,20.41-20.42$ & Includes neuroma \\
\hline \multicolumn{4}{|l|}{ Bone } \\
\hline Fracture & $\mathrm{F}$ & $30.13-30.16,30.19$ & Traumatic, includes avulsion fracture, teeth \\
\hline Physis injury & $\mathrm{G}$ & 30.20 & Includes apophysis \\
\hline \multicolumn{4}{|l|}{ Cartilage/synovium/bursa } \\
\hline Cartilage injury & $\mathrm{C}$ & $40.17,40.21,40.37$ & Includes meniscal, labral, articular cartilage, osteochondral injuries \\
\hline Arthritis & A & $40.33-40.34$ & Posttraumatic osteoarthritis \\
\hline Synovitis/capsulitis & Q & $40.22,40.34$ & Includes joint impingement \\
\hline Bursitis & $\mathrm{B}$ & 40.31 & Includes calcific bursitis, traumatic bursitis \\
\hline \multicolumn{4}{|l|}{ Ligament/joint capsule } \\
\hline $\begin{array}{l}\text { Joint sprain (ligament tear or } \\
\text { acute instability episode) }\end{array}$ & $\mathrm{L}$ or $\mathrm{D}$ & $50.01-50.11$ & $\begin{array}{l}\text { Includes partial and complete tears plus injuries to nonspecific ligaments } \\
\text { and joint capsule; includes joint dislocations/subluxations }\end{array}$ \\
\hline Chronic instability & $\mathrm{U}$ & 50.12 & \\
\hline \multicolumn{4}{|l|}{ Superficial tissues/skin } \\
\hline Contusion (superficial) & $\mathrm{V}$ & 60.24 & Contusion, bruise, vascular damage \\
\hline Laceration & $\mathrm{K}$ & 60.25 & \\
\hline
\end{tabular}

${ }^{a}$ OSIICS, Orchard Sports Injury and Illness Classification System; SMDCS, Sport Medicine Diagnostic Coding System.

A better option is to combine system/region and etiology in 1 table, as in the example on injuries shown in Table 6 . Depending on the illness pattern of the sport/setting, some region categories may be collapsed and others split further into etiology type and even to the level of specific diagnosis (where available) to highlight the most significant illnesses. We expect that subsequent sport-specific consensus statements will recommend useful standard formats for each sport.

\section{SEVERITY OF HEALTH PROBLEMS}

The severity of health problems in sport can be described using various criteria. ${ }^{33,99,104}$ These include the duration of the period for which an athlete is unable to train/play (called "time loss"), the athlete's self-reported consequences (various patient-rated measures of both health and sports performance), the clinical extent of the illness/injury, and societal cost (economic evaluation). When considering which severity criterion to use, investigators should consider the strengths and limitations of each approach related to the objectives of their study or surveillance program.

\section{Time Loss From Training and Competition}

The most widely used severity measure in sports medicine is the duration of time loss. It has been recommended in previous consensus statements ${ }^{49,52,78,102}$ and is relatively simple to capture, even when data collectors are nonexperts (coaches, parents, or athletes themselves). 
TABLE 6

Data on Injury Pattern and Burden of Specific Match Injuries Among Professional Rugby Teams in New Zealand ${ }^{a}$

\begin{tabular}{|c|c|c|c|c|}
\hline Region/Type/Diagnosis & No. of Injuries & $\begin{array}{l}\text { Incidence, Injuries/ } \\
1000 \mathrm{~h}(95 \% \mathrm{CI})\end{array}$ & $\begin{array}{c}\text { Time Loss, } \\
\text { Median (95\% CI), d }\end{array}$ & $\begin{array}{c}\text { Burden, Time-Loss Days/ } \\
1000 \mathrm{~h}(95 \% \mathrm{CI})\end{array}$ \\
\hline Head & 277 & $12.9(11.5-14.5)$ & $9(8-10)$ & $325(317-333)$ \\
\hline Concussion & 204 & $9.5(8.3-10.9)$ & $10(9-11)$ & $257(250-263)$ \\
\hline Neck & 60 & $2.8(2.2-3.6)$ & $8(6-10)$ & $135(130-140)$ \\
\hline Shoulder & 168 & $7.8(6.7-9.1)$ & $21(14-27)$ & $628(618-639)$ \\
\hline Acute dislocation & 15 & $0.7(0.4-1.1)$ & $209(27-337)$ & $165(159-170)$ \\
\hline Hematoma & 18 & $0.8(0.5-1.3)$ & $8(4-13)$ & $25(23-27)$ \\
\hline Joint sprain & 102 & $4.8(3.9-5.7)$ & $19(12-25)$ & $292(285-300)$ \\
\hline Acromioclavicular joint sprain & 54 & $2.5(1.9-3.3)$ & $14(10-20)$ & $68(65-72)$ \\
\hline Glenohumeral joint sprain & 48 & $2.2(1.7-2.9)$ & $30(14-80)$ & $225(218-231)$ \\
\hline Upper arm & 4 & $0.2(0.1-0.4)$ & $6(3-133)$ & $7(6-8)$ \\
\hline Elbow & 27 & $1.3(0.9-1.8)$ & $9(5-17)$ & $42(39-44)$ \\
\hline Forearm & 10 & $0.5(0.2-0.8)$ & $99(44-131)$ & $65(61-68)$ \\
\hline Wrist and hand & 96 & $4.5(3.6-5.4)$ & $10(7-27)$ & $194(188-200)$ \\
\hline Chest & 81 & $3.8(3.0-4.7)$ & $13(10-16)$ & $75(71-79)$ \\
\hline Thoracic spine & 6 & $0.3(0.1-0.6)$ & $5(3-50)$ & $5(4-6)$ \\
\hline Lumbar spine & 32 & $1.5(1.0-2.1)$ & $10(5-21)$ & $66(63-70)$ \\
\hline Pelvis/buttock (excluding groin) & 6 & $0.3(0.1-0.6)$ & $12(5-20)$ & $3(3-4)$ \\
\hline Hip/groin & 40 & $1.9(1.4-2.5)$ & $9(6-11)$ & $82(78-86)$ \\
\hline Thigh & 138 & $6.4(5.4-7.6)$ & $14(11-17)$ & $171(165-176)$ \\
\hline Knee & 165 & $7.7(6.6-8.9)$ & $31(23-37)$ & $544(535-554)$ \\
\hline Knee cartilage injury & 29 & $1.4(0.9-1.9)$ & $43(29-58)$ & $124(120-129)$ \\
\hline Meniscal cartilage injury & 22 & $1.0(0.7-1.5)$ & $44(28-62)$ & $101(96-105)$ \\
\hline Knee ligament injury & 125 & $5.8(4.9-6.9)$ & $30(20-37)$ & $390(382-398)$ \\
\hline MCL injury & 75 & $3.5(2.8-4.4)$ & $33(24-37)$ & $154(149-159)$ \\
\hline$A C L$ injury & 9 & $0.4(0.2-0.8)$ & $275(70-295)$ & $92(88-96)$ \\
\hline$P C L$ injury & 6 & $0.3(0.1-0.6)$ & $20(12-218)$ & $23(21-25)$ \\
\hline$P L C$ and $L C L$ injury & 8 & $0.4(0.2-0.7)$ & $35(7-132)$ & $55(52-58)$ \\
\hline Lower leg & 100 & $4.0(3.2-4.9)$ & $17(14-23)$ & $190(184-196)$ \\
\hline Ankle & 147 & $6.9(5.8-8.0)$ & $15(11-21)$ & $320(313-328)$ \\
\hline Ankle sprain & 113 & $5.3(4.4-6.3)$ & $15(11-21)$ & $228(222-235)$ \\
\hline Lateral ligament sprain & 46 & $2.1(1.6-2.8)$ & $15(9-19)$ & $78(74-82)$ \\
\hline Syndesmosis sprain & 34 & $1.6(1.1-2.2)$ & $33(28-43)$ & $108(104-112)$ \\
\hline Foot & 40 & $1.9(1.4-2.5)$ & $37(14-57)$ & $84(80-88)$ \\
\hline
\end{tabular}

${ }^{a}$ From 2005 to 2018 (unpublished data). See also Figure 5, illustrating the same data set in less detail as a risk matrix as well as the sections on rates, severity, and burden of health problems for an explanation of these concepts. ACL, anterior cruciate ligament; LCL, lateral collateral ligament; MCL, medial collateral ligament; PCL, posterior cruciate ligament; PLC, posterolateral corner.

When using this approach, we recommend that investigators record severity as the number of days that the athlete is unavailable for training and competition, from the date of onset until the athlete is fully available for training and competition.

The number of time-loss days should be counted from the day after the onset that the athlete is unable to participate (day 1) through the day before the athlete is fully available for training and competition. Therefore, cases in which an athlete does not complete a particular competition or training session but returns on the same or following day should be recorded as 0 days of time loss (see Table 10 for examples). We note that in some cases, time loss does not follow immediately after the health problem occurred and may be delayed and/or intermittent (Table 10).

When athletes recover from health problems during periods with no planned training or competition (eg, during an end-of-season break), investigators should record the end date as when the athlete normally would have been ready for full training and competition participation.
When aggregating data across athletes, severity should be reported as the total number of time-loss days, together with medians and quartiles. Means and standard deviations should be interpreted with care, given that the distribution of time-loss days is likely to be right-skewed.

When reporting data separately in severity categories, we recommend using the following time bins: 0 days, 1 to 7 days, 8 to 28 days, and $>28$ days.

If a single injury event results in multiple injuries, injury severity should be based on the injury leading to the longest time loss (eg, if a downhill skier crashes and suffers 2 injuries, a concussion that takes 10 days to resolve and a tibial fracture that takes 120 days, the time loss for the event is 120 days).

\section{Health Problems Contracted During Multiday Events}

After athletes have left an event, it may be difficult to obtain accurate follow-up information on their condition and return to play. For cases that were not closed by a date 
TABLE 7

Recommended Categories of Organ System/Region for Illnesses ${ }^{a}$

\begin{tabular}{|c|c|c|c|c|}
\hline $\begin{array}{l}\text { Organ System/ } \\
\text { Region }\end{array}$ & ICD-11 & OSIICS & SMDCS & Note \\
\hline Cardiovascular & 11 & $\mathrm{MC}$ & $\mathrm{CV}$ & \\
\hline Dermatological & 14 & MD & $\mathrm{DE}$ & \\
\hline Dental & (13) & MT & DT & \\
\hline Endocrinological & 05 & MY & $\mathrm{EN}$ & \\
\hline Gastrointestinal & (13) & MG & GI & \\
\hline Genitourinary & 16 & $\mathrm{MU}$ & GU & $\begin{array}{l}\text { Includes renal, } \\
\text { obstetrical, } \\
\text { gynecological }\end{array}$ \\
\hline Hematological & 03 & MH & $\mathrm{BL}$ & \\
\hline Musculoskeletal & 15 & MR & MS & $\begin{array}{l}\text { Includes } \\
\text { rheumatological } \\
\text { conditions }\end{array}$ \\
\hline Neurological & 08 & MN & NS & \\
\hline Ophthalmological & 09 & MO & $\mathrm{OP}$ & \\
\hline Otological & 10 & $\mathrm{ME}$ & OT & Ear only \\
\hline $\begin{array}{l}\text { Psychiatric/ } \\
\text { psychological }\end{array}$ & 06 & MS & PS & \\
\hline Respiratory & 12 & MP & $\mathrm{RE}$ & $\begin{array}{l}\text { Includes nose and } \\
\text { throat }\end{array}$ \\
\hline Thermoregulatory & (22) & MA & TR & \\
\hline Multiple systems & & MX & MO & \\
\hline $\begin{array}{l}\text { Unknown or not } \\
\text { specified }\end{array}$ & & MZ & UO & \\
\hline
\end{tabular}

${ }^{a}$ ICD-11, International Classification of Diseases-11th Revision; OSIICS, Orchard Sports Injury and Illness Classification System; SMDCS, Sport Medicine Diagnostic Coding System.

of return to play at the time of the end of the event, we recommend that:

1. If the researcher can liaise with team medical staff and record the actual date of return to play, this information should be captured. Collecting actual dates is recommended.

2. If this is not possible, then team medical staff should be asked to provide an estimate of when the athlete is expected to return to play. In such cases, this information should be clearly labeled as an estimated severity.

3. If this is not possible, then event medical staff should record the date that the athlete leaves the tournament, that is, the last date on which the athlete was seen with the unclosed health problem. In such cases, the information should clearly be labeled as rightcensored injury duration (a statistical term for situations in which only a portion of the time loss can be observed).

\section{Limitations of Using Time Loss to Measure Severity}

Time loss generally reflects injury severity but has limitations. First, the demarcation between the end of time loss and the resumption of "normal training and competition" is not necessarily a clear line in the sand. In some sports,
TABLE 8

Recommended Categories for Etiology of Illnesses ${ }^{a}$

\begin{tabular}{|c|c|c|c|c|}
\hline Etiology & ICD-11 & OSIICS & SMDCS & Note \\
\hline Allergic & $(22)$ & $\mathrm{MxA}$ & 71 & \\
\hline $\begin{array}{l}\text { Environmental } \\
\quad(\text { exercise } \\
\text { related })\end{array}$ & (23) & $\mathrm{MxE}$ & 72 & $\begin{array}{l}\text { Heat illness, } \\
\text { hypothermia, } \\
\text { hyponatremia, } \\
\text { dehydration }\end{array}$ \\
\hline $\begin{array}{r}\text { Environmental } \\
\text { (nonexercise) }\end{array}$ & $(22 / 7)$ & $\mathrm{MxS}$ & 73 & $\begin{array}{l}\text { Includes sleep/ } \\
\text { wake, sunburn }\end{array}$ \\
\hline $\begin{array}{l}\text { Immunological/ } \\
\text { inflammatory }\end{array}$ & (04) & $\mathrm{MxY}$ & 74 & \\
\hline Infection & 01 & $\mathrm{MxI}$ & 75 & $\begin{array}{l}\text { Viral, bacterial, } \\
\text { parasitic }\end{array}$ \\
\hline Neoplasm & 02 & $\mathrm{MxB}$ & 76 & \\
\hline $\begin{array}{l}\text { Metabolic/ } \\
\text { nutritional }\end{array}$ & 05 & $\mathrm{MxN}$ & 77 & \\
\hline $\begin{array}{l}\text { Thrombotic/ } \\
\text { hemorrhagic }\end{array}$ & $(11 / 03)$ & $\mathrm{MxV}$ & 78 & \\
\hline $\begin{array}{l}\text { Degenerative or } \\
\text { chronic } \\
\text { condition }\end{array}$ & - & $\mathrm{MxC}$ & 79 & $\begin{array}{l}\text { Chronic acquired } \\
\text { conditions }\end{array}$ \\
\hline $\begin{array}{l}\text { Developmental } \\
\text { anomaly }\end{array}$ & 20 & MxJ & 80 & $\begin{array}{l}\text { Includes congenital } \\
\text { conditions }\end{array}$ \\
\hline $\begin{array}{l}\text { Drug-related/ } \\
\text { poisoning }\end{array}$ & 22 & $\mathrm{MxD}$ & 81 & $\begin{array}{l}\text { Includes } \\
\text { pharmaceutical, } \\
\text { illicit }\end{array}$ \\
\hline Multiple & & $\mathrm{MxX}$ & 82 & \\
\hline $\begin{array}{l}\text { Unknown or not } \\
\text { specified }\end{array}$ & & MxZ & 83 & \\
\hline
\end{tabular}

${ }^{a}$ ICD-11, International Classification of Diseases-11th Revision; OSIICS, Orchard Sports Injury and Illness Classification System; SMDCS, Sport Medicine Diagnostic Coding System.

athletes may be able to participate before an injury or illness has fully resolved, for example, by adapting their technique, accepting a lower performance level, or playing a different role on the team (eg, a ballet dancer working at the barre but not dancing on the floor or doing any jumps). Participation before an injury or illness is fully resolved would tend to underestimate the absolute severity of the injury if one considered full healing as the gold standard. Conversely, athletes may choose not to resume their "normal" training and competition for an extended period after an injury or illness has clinically resolved to allow them to regain full fitness (eg, a professional football player after ACL reconstruction). This would overestimate the severity of the condition.

Second, a time loss-based severity measure underestimates the severity of those health problems that limit a player's performance but do not stop the person from playing. Many gradual-onset injuries fit that bill (eg, patellar tendinopathy). Similarly, when athletes have a recurrent or chronic illness, such as asthma or inflammatory arthritis, they may have relatively low time loss (from training or competition) but may be markedly affected in training content and intensity. ${ }^{3,16,17}$

Third, time loss is inappropriate to describe the most severe types of health problems, such as those leading to 
TABLE 9

Recommended Categories of Illness Symptom Clusters for Athlete Self-reports or Nonmedical Data Reporters

\begin{tabular}{|c|c|}
\hline System/Region & Symptom Cluster \\
\hline Upper respiratory (nose, throat) & $\begin{array}{l}\text { Runny nose, congestion, hay fever (allergy), sinus pain, sinus pressure, sore throat, cough, } \\
\text { blocked/plugged nose, sneezing, scratchy throat, hoarseness, head congestion, swollen } \\
\text { neck glands, postnasal drip (mucus running down the back of the nose to the throat) }\end{array}$ \\
\hline Lower respiratory & $\begin{array}{l}\text { Chest congestion, wheezing (whistling sound), chesty cough, chest pain when breathing/ } \\
\text { coughing, short of breath, labored breathing }\end{array}$ \\
\hline Gastrointestinal & $\begin{array}{l}\text { Heartburn, nausea, vomiting, loss of appetite, abdominal pain, constipation, weight loss } \\
\text { or gain ( }>5 \mathrm{~kg} \text { in the past } 3 \text { months), change in bowel habits, diarrhea, blood in the stool }\end{array}$ \\
\hline Cardiovascular & $\begin{array}{l}\text { Shortness of breath, racing heart beats, irregular or abnormal heart beats, chest pain, } \\
\text { chest pain or discomfort with exercise, dizziness, fainting spells, blackouts, collapse }\end{array}$ \\
\hline Urogenital/gynecological & $\begin{array}{l}\text { Burning urination, blood in urine, loin pain, difficulty in passing urine, poor urine stream, } \\
\text { frequent urination, genital sores, loss of normal menstruation, irregular or infrequent } \\
\text { menstruation, menstrual cramps/pain, excessively long periods, excessive bleeding } \\
\text { during periods, vaginal discharge, penile discharge, swollen groin glands }\end{array}$ \\
\hline Neurological & $\begin{array}{l}\text { Headache, fits or convulsions, muscle weakness, nerve tingling, nerve pain, loss of } \\
\text { sensation, chronic fatigue }\end{array}$ \\
\hline Psychological & $\begin{array}{l}\text { Anxiety, nervousness, excessive restlessness, feeling depressed (down), excessive sadness, } \\
\text { not sleeping well, mood swings, feeling excessively stressed }\end{array}$ \\
\hline Dermatological & $\begin{array}{l}\text { Skin rash, dark/light/colored areas on the skin that have changed in size or shape, itchy } \\
\text { skin lesions }\end{array}$ \\
\hline $\begin{array}{l}\text { Musculoskeletal, rheumatological, and connective } \\
\text { tissue (unrelated to injury) }\end{array}$ & $\begin{array}{l}\text { Joint pain, joint stiffness, joint swelling, muscle twitching, muscle cramps, muscle pain, } \\
\text { joint redness, warmth in a joint }\end{array}$ \\
\hline Dental & $\begin{array}{l}\text { Toothache, painful gums, bleeding gums, oversensitive teeth, persistent bad breath, } \\
\text { cracked or broken teeth, jaw pain, mouth sores }\end{array}$ \\
\hline Otological & $\begin{array}{l}\text { Ear pain, ear discomfort, loss of hearing (new onset), deafness, discharge from the ear } \\
\text { canal, bleeding from the ear canal, ringing in the ears }\end{array}$ \\
\hline Ophthalmological & $\begin{array}{l}\text { Pain in eye, itching or burning eye, scratchy eye, eye discharge, change in vision including } \\
\text { double vision, blood in eye, excessive tearing, abnormal eye movements, swelling of eye, } \\
\text { blind spot in eye, drooping eye, halo around lights, lightning flashes, swelling of eyelid }\end{array}$ \\
\hline Nonspecific illness & Feeling feverish, chills, pain, whole body aches, feeling tired \\
\hline $\begin{array}{l}\text { Energy, load management, and nutrition } \\
\text { (nonbody system) }\end{array}$ & Unexplained underperformance, reduced ability to train and compete, fatigue \\
\hline
\end{tabular}

retirement from sport, permanent disability, or death, because the time-loss data from those injuries are rightcensored.

\section{Athlete-Reported Symptoms and Consequences}

There are tools to measure injury and illness symptoms that directly address the second limitation of time loss discussed earlier, underestimating the effect of ongoing pain and symptoms that are below the time-loss threshold. A tool such as the Oslo Sports Trauma Research Center Questionnaire on Health Problems (OSTRC-H) complements time-loss measures of severity, as it also captures symptoms and functional consequences of injury and illness. This purpose-built instrument was devised in $2013^{17}$ and updated in $2020^{15}$ and has played an increasing role in sports injury and illness surveillance, especially in sports and settings where overuse injuries and illnesses represent a substantial burden on health and performance. ${ }^{71}$

The tool (which can be delivered via a mobile application) invites athletes to record reduced sports participation, training modifications, performance reductions, and symptoms. ${ }^{17}$ Based on the response to these questions, researchers can calculate a severity score ranging from 0 to 100 at specific time points. These can be aggregated (summed as the area under the curve) to monitor injury and illness over time (Figure 4). This is called the cumulative severity score. A limitation of this method is that the severity score is an arbitrary number, and it has not been thoroughly validated as a proxy for injury severity.

\section{Recording the Severity of Health Problems Based on Clinical Assessment}

Investigators may also report the severity of health problems based on clinical outcomes such as the need for hospitalization or surgery, ${ }^{33,92}$ retirement from sport, permanent disability, or death. ${ }^{43,92}$

Degree and Urgency of Medical Attention. The severity of an injury or illness can also be recorded based on the degree and urgency of medical attention received by the athlete. This approach is best suited to record acute conditions and is often used in mass-participation events and community sports settings. ${ }^{33,40,41}$ An example using this approach is provided by Schwellnus et $\mathrm{al}^{92}$ in their work on mass community-based endurance sports events. 
TABLE 10

Practical Examples of How to Calculate Time Loss

\begin{tabular}{lc}
\hline & $\begin{array}{c}\text { Time } \\
\text { Case }\end{array}$ \\
\hline Loss, d \\
\hline A collegiate volleyball player is substituted from a match & 0 \\
because of an injury but returns to compete in another & \\
match later the same day. & \\
A cyclist interrupts a training session because of mild & 0 \\
diarrhea and resumes normal training the & \\
following day. & \\
A hockey player strains her hamstring during a training & 6 \\
session on Monday and returns to normal training on & \\
Monday of the following week. & \\
A recreational-level cricket player injures his shoulder & 2 \\
during a match on Saturday. His shoulder is stiff and & \\
painful for 2 days after the match (Sunday and & \\
Monday). The team only trains once per week, every & \\
Thursday, but the player feels that he would have been & \\
able to train normally had training been on Tuesday & \\
instead. & \\
"Delayed" time loss: An athlete suffers an injury on & 3 \\
Sunday, a thigh contusion, is able to train on Monday & \\
and Tuesday, but is unable to train on Wednesday and & \\
returns on Sunday (time loss starts on Wednesday, & \\
even though the injury occurred on Sunday). & \\
"Intermittent" time loss: A player with Osgood-Schlatter & 2 \\
disease that gets reported at the start of a training & \\
camp on Monday. He may train fully on Monday, & \\
Tuesday, and Thursday but miss training on & \\
Wednesday and Friday (time loss counted as & \\
Wednesday and Friday only). & \\
\hline
\end{tabular}

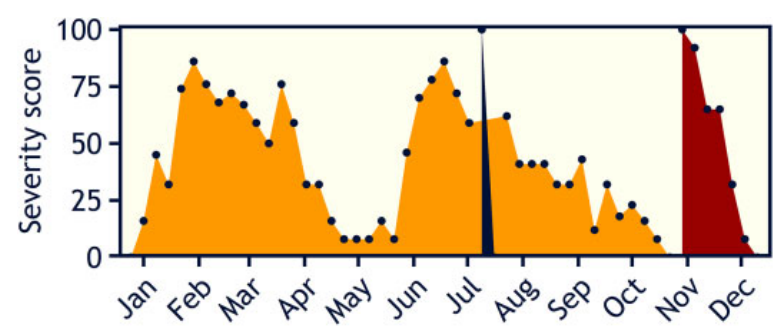

Figure 4. Example of severity scores being used to track the severity of 3 "typical" health problems. Each black dot represents the weekly severity score. The area in orange represents a gradual-onset injury (cumulative severity score [sum of weekly scores, as the area under the curve] =1820), the black area represents a short-duration illness (score $=100$ ), and the dark red area represents an acute medial collateral ligament injury (score $=362) .{ }^{17}$

Permanent Disability and Death. All conditions leading to permanent disability or death that occur during the period of data collection should be reported separately. There are some specific definitions accepted in the field:

- A "catastrophic injury" refers to a confirmed spinal cord or traumatic brain injury, resulting in permanent functional disability (using the American Spinal Injury Association scale ${ }^{2}$ and assessed at 12 months).
This does not include injuries resulting in transient neurological deficits such as burners/stingers, paresthesia, transient quadriplegia, or cases of concussions in which there is full recovery. The term "catastrophic event" has also been extended to include noninjury events that are life-threatening, such as sports-related sudden cardiac arrest and exertional heat stroke. ${ }^{28}$ More detailed recommendations on this issue are provided in the consensus statement on mass community-based endurance sports events. ${ }^{92}$

- A "fatality" refers to any athlete fatality related to training or competition. When fatalities occur months or years after the event, researchers should justify the relationship to training/competition. ${ }^{43,66}$

As such cases often receive media attention, we remind investigators to consider privacy issues. Special considerations apply to approaching, consenting, and collecting data from families who have sustained a major loss.

\section{Other Severity Measures}

Depending on the sport setting and the purpose of data collection, investigators may also quantify severity in other ways. ${ }^{99}$ Function, performance, and patient-reported outcome measures may be used to capture severity. Specific examples include the following:

- Functional measures, for example, the International Classification of Functioning, Disability and Health (ICF). ${ }^{113}$

- Sports-related performance measures, for example, balance, strength, and endurance. We include athletes reporting retirement from sports in this category.

- Patient-reported outcome measures, for example, the ACL Quality of Life Questionnaire (ACL-QOL), ${ }^{75}$ Knee injury and Osteoarthritis Outcome Score (KOOS), ${ }^{89}$ and Sport Concussion Assessment Tool5 th Edition (SCAT5). ${ }^{23}$

\section{CAPTURING AND REPORTING ATHLETE EXPOSURE}

Assessing exposure is fundamental to quantifying injury and illness risk in sports. ${ }^{33,46}$ There are many ways to quantify athletic exposure, and no single measure will suit all surveillance settings and research questions. The choice of exposure measures is heavily influenced by sport-specific and contextual factors as well as which types of health problems are of interest. Therefore, it is often necessary to record exposure in several ways.

\section{Tracking Exposure for Injury Analyses}

For injuries, exposure is generally quantified as the time during which athletes are at risk of injury (eg, minutes played), the distance covered, or a count of the number of 
specified events (eg, tackles, throws, or jumps). In some sports, exposure is commonly expressed as the number of athletic participations (eg, games, races, training sessions), often referred to as "athletic exposures." Table A2 in Appendix 1 provides a range of examples of exposure measures used.

In team sports, we recommend recording exposure for each individual within a team rather than merely estimating the number of matches that the team plays and match duration (team exposure) because the former permits the researcher to examine individual risk factors. Results of all the individuals are then summed to provide exposure at the sport or team level.

As the injury risk is often markedly different between training and competition, these exposures should be recorded and reported separately. To do this consistently, it is necessary to define competition and training and to consider situations where applying the definition may be challenging.

We define competition as organized scheduled play between opposing athletes or teams of athletes or as athlete(s) competing (1) against time and/or (2) to obtain a score (judged or measured). We define training as physical activities performed by the athlete that are aimed at maintaining or improving their skills, physical condition, and/or performance in their sport.

In many sports, it is common to simulate competition as a part of training. Examples include preseason "friendly scrimmages" between 2 teams or dividing a single squad into teams that compete against each other. In general, this should be counted as training exposure. Additionally, activities such as warm-up and cool-down should be counted separately and reported as training injuries, even if occurring around competition.

It is likely that, in some sports, these definitions will not be fully applicable. In such cases, we encourage sportspecific consensus groups to define what constitutes competition and training in that sport.

\section{Tracking Exposure for Illness Analyses}

Because athletes remain at risk of developing an illness even when they are not participating in sports, it is inappropriate to use exposure measures such as playing hours or movement counts to quantify the illness risk (except for the rare cases of transmissible infections that are specific to participation in a sport; eg, scrum pox). Instead, it is often most appropriate to use exposure measures based on the time that athletes are under surveillance (days or years) rather than time engaged in competition and training.

\section{Recording Exposure During Multiday Competitions}

Multiday competitions, such as championships and tournaments, represent an exposure measurement challenge, particularly for injury analyses. Ideally, investigators should obtain accurate records of every athlete's individual participation (eg, training and competition minutes) throughout the tournament. However, this is not always feasible. Acceptable exposure estimates can also be made by obtaining summary data from every team for each day of the tournament (eg, squad numbers). As a minimum standard, exposure can be estimated for each event by multiplying the number of registered athletes by the duration of the tournament (the number of days of competition). In multisport tournaments, this should be calculated for each sport. However, this approach assumes that all athletes have the same exposure and participate every day, which is rarely the case.

\section{Training Subcategories}

Different types of training should, if possible, be recorded and reported separately. Training types can be generally categorized as follows:

- Sport-specific training: sessions involving the techniques and/or tactics of the sport, usually supervised by a coach.

- Strength and conditioning: sessions solely composed of resistance training and/or conditioning training. In many cases, training sessions are mixed (sportspecific, but with the addition of some strength and conditioning; eg, plyometrics and endurance). As a pragmatic consideration, any session containing sport-specific training should be categorized as such, even if the session includes some strength and conditioning, purely to streamline exposure tracking.

- Other training sessions: sessions that include activities other than sport-specific training or strength and conditioning. These include recovery sessions (eg, low-intensity running and stretching), rehabilitation, and postrehabilitation transition sessions (after return to sport but prior to resuming normal training).

Sport-specific injury surveillance systems may need to depart from this guidance if there is a need to address a specific training concern; however, at a minimum, all training exposures that contain sport-specific training should be tracked.

Sport-specific injury surveillance systems are encouraged to develop specialized procedures for tracking the diversity of training exposures in their particular sport. Training programs vary considerably among sports, and many coaches intentionally design training programs that integrate multidimensional training (eg, plyometric stretching, sport-specific training, light running) into a single session. In general, investigators should prioritize capturing specific data on the training activities considered to present the greatest health risk.

Wearable physical activity tracking devices enable investigators to capture large volumes of competition and training data at the elite level and from community sports participants across large sample groups. We encourage the use of these devices for tracking exposure. However, we caution that any device needs to be fit for the purpose, and researchers should obtain evidence on their validity and 
reliability before data collected through these devices are used for injury surveillance.

\section{EXPRESSING RISK}

\section{Rates and Proportions}

Rates and proportions of injury and illness in studies of sports are usually reported as counts of "cases" of the outcome of interest (the "numerator") divided by a population at risk of developing the outcome (the "denominator"). ${ }^{18}$ Because research questions such as "How many players have suffered a knee injury?" "What is the risk of getting injured in this sport?" and "How does sport A compare with sport B for concussion risk?" are very different, there are various ways of reporting risks related to sports injury and illness. We explain some fundamental terms here.

Prevalence: How Many? Prevalence is a proportion and refers to the number of existing cases divided by the total population at risk at a given point in time (point prevalence; eg, the proportion [percentage] of players on a volleyball team who, today, are suffering from patellar tendinopathy). It is a snapshot at one point in time but can be repeated to determine changes in prevalence over time (eg, weekly). With serial measurements, it is possible to report, for example, the average prevalence over the course of the season and also to compare different stages of the season.

Period prevalence extends the concept of a single point in time to a window of time (eg, 1 season, 1 year). It refers to the proportion of athletes that has reported the condition of interest (eg, patellar tendinopathy) at any time during that given window. Notably, this includes people who already had the condition at the start of the study period as well as those who acquired it during that period.

Incidence: How Often (Do New Cases Occur)? Incidence is a rate, and as with any rate, time comes into play. Incidence refers to the number of new injuries/illnesses in the population that develop during a defined period of time. The term "incidence rate" is synonymous, but we argue that it is a tautology; "incidence" is a rate.

Note that prevalence is calculated based on the number of athletes with a health problem, while incidence refers to the number of new health problems.

\section{Recommendations: Expressing Risk in Sports Injury/lllness Surveillance}

Incidence-based measures usually represent more appropriate outcomes for sudden-onset conditions (eg, ankle sprains, ACL injuries) and prevalence-based measures for gradual-onset conditions (eg, asthma, patellar tendinopathy). ${ }^{3}$ Overuse injuries and pain problems such as low back pain and patellar tendinopathy are often chronic, with periods of remission and exacerbation. For example, in a professional volleyball team, there could be only 1 new case of patellar tendinopathy (so the incidence will be low), yet $40 \%$ of the players (nearly all pre-existing) could be affected by patellar tendinopathy during the season (period prevalence). Therefore, for such conditions, prevalence (the proportion of athletes affected) is a more appropriate measure than incidence (the number of new cases during the season).

Because sports and the activities that comprise them are so diverse, there is no single approach to expressing risk appropriately for all sports injury surveillance projects. ${ }^{70}$ In general, incidence-based measures that provide a standard time window for the population at risk (injuries per hour) are preferable to measures for which the time at risk varies across individuals (injuries per athletic exposure, ie, per training session or match) because time-based measures better facilitate comparison across sports.

To provide numbers that are easy to interpret, avoiding small decimals, these data are typically reported as per 1000 player-hours (eg, the concussion rate in a men's rugby study was reported as 4.7/1000 player-hours rather than 0.0047 per player-hour). ${ }^{55}$ Such numbers allow risks to be compared (eg, how does the concussion risk vary across contact sport codes?). We expect that subsequent sportspecific statements will recommend suitable, standard incidence-based measures for each sport. Table A2 in Appendix 1 provides a range of examples of risk measures.

If 1 injury event results in multiple injuries, these should only be counted as 1 when calculating overall injury incidence (eg, if a downhill skier crashes and suffers 2 injuries, a concussion and a tibial fracture, these are counted as 1 injury when calculating incidence).

Because of the difficulties in accurately measuring exposure to pathogens (which may be greater when not training or competing), illness risk should be estimated based on the entire period of exposure (eg, the duration of a competition, a "season of play," a year), not athletic exposure only. We recommend reporting illness risk as either the incidence; the number of new cases divided by a period of time (eg, illnesses per 365 athlete-days $)^{91}$; or as the period prevalence of the illness, the proportion of athletes who were ill during a defined period. ${ }^{94,95}$

Where time-based measurements of exposure are unavailable but participant numbers are available, crude rates of injury per number of participants per period can be derived. In such cases, we suggest that the incidence that may be most useful to permit population-level comparisons among sports or studies is "injuries per 365 athlete-days."

Similarly, the proportion of participants with new or recurring injury or illness (ie, excluding pre-existing cases and exacerbations) during the event has been used to provide an impression of the risk associated with participation in each sport in both the summer and winter Olympic Games. ${ }^{94,95}$ However, this approach-period prevalencecan suggest widely different relative risks of activities that differ substantially in the amount of exposure participants experience. ${ }^{94}$ For example, exposure differs substantially between a football player and a sprinter. Period prevalence describes the absolute risk of participation in the Olympic Games but not the relative risk (the risk of injury during 1 hour of football play vs 1 hour of marathon running).

Injury rates reported on a per-event (eg, per rugby tackle) basis provide information about how likely a particular aspect of play (event) is to result in an injury. 
Understanding events that both $\mathrm{do}^{5}$ and do not result in injury ${ }^{73,74}$ helps researchers identify injury prevention opportunities. In the absence of information about how frequently the event occurs within a sport and the average duration of the sport to which participants are exposed, rates per event also provide an incomplete view of the overall risks that a sport poses. Using time- and event-based denominators (eg, tackles in football codes) in parallel can help provide insights into both which event (eg, tackle type) is most frequently associated with injuries and which event carries the highest risk when it occurs. To date, there have been relatively few injury surveillance studies in which such statistics have been provided together. ${ }^{44}$ For televised sports and those using new technology such as activity trackers, measurement of the duration of playing time and intensity for each athlete is feasible, and coding of the number, characteristics, and duration of activities each participant engages in (eg, tackles) is routine for some professional sports (eg, football). We include a real-life illustrative case of surveillance methods being used to investigate injury risk in rugby in Appendix 1.

\section{Communicating the Risk to Stakeholders}

From clinical and practical perspectives, it is important that the end users (the athletes, coaches, and medical staff members) can make sense of the injury reports and increase the chances of having them participate in risk management plans. This can be done by expressing the injury incidence based on the concerned sport's specifications. For instance, if an injury incidence for a specific muscle group (eg, hamstring) is expressed as 0.9 injuries per 1000 hours of exposure, the incidence per player per season (0.28 injuries/player/season) could be multiplied by the average number of athletes per squad for the concerned sport (eg, 25 in football). This gives 7 hamstring injuries per squad per season, a quantity that is more easily interpreted by end users.

Another relevant measure, which is easy to communicate to managers, coaching staff, and athletes and that is associated with team performance in football, ${ }^{59}$ is player availability. Player match availability is calculated as the sum of player match opportunities (ie, the number of matches multiplied by the full size of the squad) minus the sum of player match absences due to injury or illness and can be expressed as the average percentage over the period of interest (eg, 1 season). Training availability can be calculated in the same way.

We encourage sport-specific consensus statements to recommend relevant measures to communicate risk to relevant stakeholders.

\section{BURDEN OF HEALTH PROBLEMS}

Burden is a collective measure of the overall impact of a health problem in a specified population. In public health, burden is often expressed by financial cost, mortality, or morbidity. One common approach is specific measures such as quality-adjusted life years or disability-adjusted life

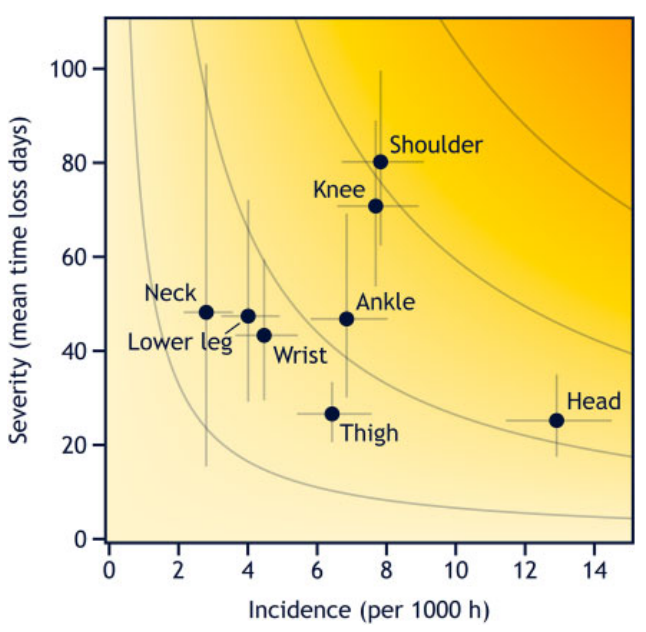

Figure 5. Risk matrix based on the duration of time loss illustrating the burden of match injuries among professional rugby teams in New Zealand between 2005 and 2018 (unpublished data). The darker the yellow, the greater the burden. The curved gray lines represent points with equal burden. The vertical and horizontal error bars represent $95 \% \mathrm{Cls}$. See also Table 6, illustrating the same dataset in more detail.

years. ${ }^{79}$ Burden allows different health problems to be compared-Does low back pain or diabetes cause more burden to society?

The burden of injuries and illnesses can also be expressed using measures that combine their frequency and consequences. ${ }^{4,21}$ For example, in football and rugby union, injury burden has been reported as the number of days of time loss per 1000 hours of player exposure. ${ }^{8-}$ $12,87,110$ This contrasts with incidence (discussed earlier), where the numerator is the number of injuries rather than the consequence of those injuries-days of time loss.

As measures of incidence and consequences vary depending on the purpose and setting of data collection, there is no single method of calculating burden in sports. To facilitate comparison among sports, investigators should consider reporting the number of days of time loss per 365 athletedays for each outcome of interest in addition to measures based on sport-specific exposures. We expect that subsequent sport-specific statements will provide recommendations on suitable, standard burden measures for each sport.

Burden can also be visualized using a risk matrix in which the incidence of each health problem of interest is plotted against its consequences (such as mean time loss, as illustrated in Figure 5). This is an effective way to communicate the overall burden (and its determinants) for a range of health problems. However, there are certain limitations to interpreting risk matrices, depending on how figures are designed and how data are structured (see Fuller ${ }^{47}$ for a detailed review).

Burden measures that use time loss as a measure of severity fail to incorporate the most severe health problems (ie, fatalities and nonfatal catastrophic injuries and illnesses) and other cases where the athlete fails to return 


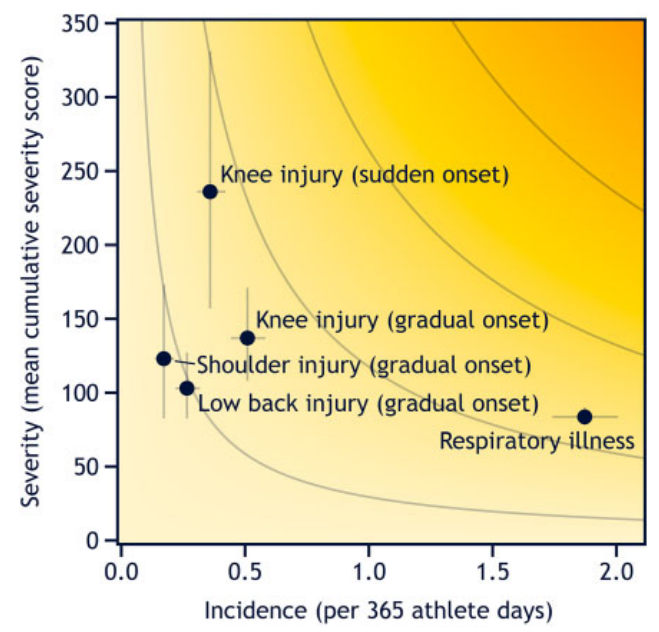

Figure 6. Risk matrix based on Oslo Sports Trauma Research Center Questionnaire on Health Problems severity scores illustrating the burden of injuries and illnesses affecting elite Norwegian endurance athletes (unpublished data). Error bars represent $95 \% \mathrm{Cls}$.

to sport (eg, due to retirement). As previously discussed, time loss-based severity measures also underrepresent overuse injuries and chronic illnesses. ${ }^{3,16}$ In this case, mean OSTRC-H severity scores can be used instead of time loss, as illustrated in Figure $6 .^{15}$

\section{STUDY POPULATION CHARACTERISTICS}

Depending on the purpose of the study, demographic and health data may be included in injury and illness surveillance protocols. The demographic information captured should, as a minimum, include age, sex, and level of competition and disability/impairment type in Paralympic sport. These can be supplemented with data on other relevant characteristics that could help investigators evaluate risk factors.

It is important to describe the performance and training level of the study population both because they are often closely related to health outcomes and to allow appropriate studies to be compared. ${ }^{33}$ It is beyond the scope of this consensus group to provide a universal classification of competitive level. For example, the criteria used to define "elite" vary considerably among sports. We encourage sport-specific methodological consensus groups to define what constitutes "elite," "subelite," and "recreational" athletes in their sport.

\section{Classification of Sport Categories}

There are many ways of classifying and grouping sports. Any sports classification system used in surveillance should be clearly described in the methods section of reports. The description should permit other researchers to understand and replicate the process by which sports were grouped. The research problem being addressed should shape the classification system used rather than vice versa.

\section{DATA COLLECTION METHODS}

The methods underpinning the data collection have great impact on the outcome of sports injury and illness surveillance studies. ${ }^{33,38,97}$ A systematic review of ongoing injury surveillance systems in sport found that data quality aspects were published for only 7 of the 15 systems and validation studies for only $4 .^{26}$ The review concluded that data quality could be improved through the establishment of data collection standards.

Given the wide range of settings in which surveillance is undertaken, data collection methods should be flexible enough to adapt to the specific context (eg, sport culture, level of sport, availability of resources) and to the specific research question and objectives of the study. ${ }^{33}$ These factors in combination will determine:

- Who should provide the information (eg, athlete, physician, physical therapist, coach, nonclinical volunteer)

- What data sources should be used (eg, athlete selfreport, medical records, examinations, video recording)

- The frequency of data collection and reporting (eg, daily, weekly, monthly)

- The timing of and window for data collection (eg, day of injury/illness or of competition/training or following day, within a week)

- The duration of surveillance (eg, tournament, season, whole year, playing career)

Taking all of these variables into account, it is evident that "one size does not fit all."14,105

In 2001 , the $\mathrm{WHO}^{38,62}$ published guidelines for injury surveillance that remain relevant. In particular, some general aspects about quality of data collection systems (ie, objectivity, reliability, validity, practicability, risk of bias, cost-/time-effectiveness, acceptability), quality of implementation (eg, guidance document, communication, compliance, data check), and some methodological issues (eg, handling of missing values, completeness of reports, coverage, response rate) are important. ${ }^{24,36,64}$ In addition, the choice of injury definition, exposure measure, and methods used to express rates influence the results substantially, as discussed in the relevant sections of this document.

The reliability of the system can be improved by tailored education, ongoing support for the people who report the data, and a detailed process manual ${ }^{62}$ and should be evaluated at least by analysis of interrater reliability of people reporting the data. ${ }^{24}$

Validity and completeness of data reporting can be analyzed, comparing with another "gold-standard" data source. ${ }^{6,42,53,67,77,81}$ A recent study showed that researchinvolved staff recording the data in a surveillance program reported a greater number of mild injuries than did nonresearchers. ${ }^{109}$ 
TABLE 11

Implementation Recommendations for Injury/Illness Surveillance

The implementation of an injury and illness surveillance project should include the following aspects:

Methods based on this consensus statement on definitions and data collection procedures

Mandatory standards for compliance with defined time scales for completion for report forms

Guidance document (a quality protocol) shared with all club/ national team medical staff (preseason/tournament)

Regular contact between study lead and responsible person at each club/national team (face-to-face meeting preseason/prior to tournament, conference call midseason/tournament)

All injuries cross-checked with club/team medical records and followed up with medical staff for missing, incomplete, inconsistent, or duplicate entries (regularly during season/ tournament)

Data cleaning and final review of dataset with responsible person at each club/team before definitive analysis (end of season/ tournament)

Injury reports where individual club/team data are reported, analyzed, and compared with the average of all participating clubs/teams (midseason and end of season/tournament)

Medical meeting (end of season/tournament) where whole surveillance results and translational value are presented to club/team medical practitioners for discussion

An example of specific measures to improve the reliability of a surveillance project is illustrated in Table 11, based on the procedure of the Professional Rugby Injury Surveillance Project. ${ }^{29}$

\section{From Pen and Paper to Electronic Solutions}

Health problems and exposure can be captured using different methods ranging from paper copy data collection forms to a comprehensive web-based surveillance system, for example, internet platforms, mobile applications, or text messaging. ${ }^{7,31,40,76,77,81,96,117}$ The traditional pen-andpaper approach is often easy to implement, ${ }^{41}$ as it reduces the need for specific technical knowledge, equipment, and related costs. ${ }^{40,72}$ Data can be verified and cleaned as they are manually entered. ${ }^{72}$

Electronic data capture reduces time for the duplication of data entry ${ }^{41}$ and associated entry errors. ${ }^{72}$ In terms of costs, there is potential long-term cost-effectiveness through the elimination of expenses linked to the printing, shipping, management, and storage of physical documents. ${ }^{72}$

Web-based solutions allow instant and remote ondemand queries of real-time data (including end users such as team medical staff) as well as integration with other data feeds (eg, performance, load, sleep). Web-based solutions should preferably be prototyped prior to being implemented in a larger injury surveillance setting. Full integration of surveillance reporting systems within clinical electronic medical record-keeping systems has been used successfully in a number of professional elite leagues. ${ }^{22}$ While electronic solutions can lead to high response rates among athletes, ${ }^{76,77,81}$ there are also reports of poor athlete engagement, ${ }^{7}$ and thus demonstrates the importance of understanding uptake barriers. It is important to use surveillance tools that minimize intrusion into the daily activities of the data reporters (athletes, medical teams, coaches), for example, by limiting the number of questions to responders so that only essential data are captured. Another recommendation is to provide a clear incentive to athletes and teams to participate in injury surveillance, for example, by allowing continuous feedback within the data collection system (eg, performance data, load monitoring data) or sending regular reports back to the teams, athletes, and other relevant stakeholders. ${ }^{25}$

Data collection methods must be adapted to the specific research question, the sport context, and the skill set of the research team and should follow strict quality standards. The quality of the surveillance system includes the quality of the forms (baseline, health problems, and exposure) as well as the quality of the data collection procedure, implementation, data cleansing, and analysis methods. ${ }^{40}$ The quality and usability of the forms and the data collection procedures should be examined before implementation. Reliability and validity should be analyzed, and all translations should follow the standards of intercultural adaptation. ${ }^{54,61}$ The adherence to the data collection protocol as well as the completeness and consistency of responses should be monitored on a regular basis during implementation. Collaboration between research groups to share resources and joint data analytics can help advance the management of sport injuries/illnesses. ${ }^{103}$ Having data collection forms and related material available in free-to-access formats makes it easier for sports bodies to participate in surveillance activities, ${ }^{40}$ and this consensus statement includes some sample forms as mentioned in Appendix 2.

\section{Research Ethics and Data Security}

Research ethics govern the conduct of medical research and aim to protect the dignity, rights, and welfare of human participants. They detail principles such as informed consent, data confidentiality, the use of research ethics committees and risks, burdens, and benefits. Importantly, informed consent is the process in which permission is granted in full knowledge of the possible consequences (risks and benefits), for example, for their data to be used for research purposes. In some contexts, injury and illness surveillance may be regarded as an integral part of data audit and quality control processes and, as long as individual patient data are fully deidentified, may not require informed consent. It is the duty of all researchers (and all other users of the data) to consider, and adhere to where appropriate, internationally recognized guidelines for research ethics (such as the Declaration of Helsinki ${ }^{115}$ and the Declaration of Taipei ${ }^{116}$ ).

Data protection governs how data are collected, shared, used, and conserved and aims to ensure that personal data are safe from unforeseen, unintended, or malevolent use. Particular attention must be directed to the security of data stored on cloud-based systems and other electronic repositories. Researchers must adhere to the data protection 
regulations applicable to their context (such as the General Data Protection Regulation in Europe). ${ }^{30}$

\section{REPORTING GUIDELINES: STROBE SPORTS INJURY AND ILLNESS SURVEILLANCE}

The statement on STROBE was published in 2007. ${ }^{106}$ Since then, it has been adapted (extensions) to ensure the statement is relevant to other areas of interest such as infectious diseases ${ }^{32}$ and most recently (2018) for pharmacoepidemiology. ${ }^{68}$ These extensions of STROBE have stressed, like the original, that they only guide on how to report findings from observational studies rather than guiding study design. However, the two are related, and researchers are strongly encouraged to consider the elements of the checklists when planning studies; this may eventually improve study quality and ensure that researchers are able to report what is needed at the end of the study. STROBE has checklists for the 3 most common study types: cohort studies, case-control studies, and cross-sectional studies. Here, we summarize our consensus recommendations on the collection and reporting of SIIS data as an extension to the initial STROBE checklist. These apply regardless of study design. Note that many other study designs common in sports and exercise medicine research, such as randomized controlled trials, should be reported against other reporting standards (like CONSORT, which will be refreshed in 2020). ${ }^{19}$ As most sports medicine studies rely on surveillance methods to collect injury and illness outcome data, the recommendations in this consensus statement apply widely.

To guide researchers in the field of sport and exercise medicine, we have adapted (extended) the STROBE checklist so that it reflects recommendations from this current IOC consensus statement on studies of injury and illness surveillance in sports. This extension refers to 21 of the original items. It includes only items specific to the reporting of injuries and illnesses in sport, as amendments to reflect broader epidemiology methodology developments should be more appropriately documented by the EQUATOR Network, which oversees STROBE.

It is intended that this new checklist, the STROBE-SIIS, will help researchers design an injury/illness surveillance study and plan the study protocol as well as better report their observations (Appendix 3). By consistently using the STROBE-SIIS, authors ensure that other researchers will be able to more easily replicate, compare, and synthesize sport and exercise medicine research studies.

We also strongly recommend that researchers publish their study protocols ahead of study completion, ideally with an open access formal register, and also report on any changes made to the initial protocol during study conduct, together with their rationale for the change, once the study has been completed. Details of where protocols and their amendments are publicly available should be stated in papers submitted for publication.

Feedback on this checklist is welcome, and we will both monitor and evaluate the impact of its use over time. We welcome researchers with relevant expertise to translate this checklist to other languages for the benefit of the international sports medicine community.

\section{AUTHORS}

International Olympic Committee Injury and Illness Epidemiology Consensus Group; Roald Bahr, MD, PhD (Oslo Sports Trauma Research Center, Department of Sports Medicine, Norwegian School of Sport Sciences, Oslo, Norway; Aspetar Orthopaedic and Sports Medicine Hospital, Doha, Qatar); Ben Clarsen, PT, PhD (Oslo Sports Trauma Research Center, Department of Sports Medicine, Norwegian School of Sport Sciences, Oslo, Norway; Department of Health Promotion, Norwegian Institute of Public Health, Bergen, Norway); Wayne Derman, MD, PhD (Institute of Sport and Exercise Medicine, Division of Orthopaedic Surgery, Faculty of Medicine and Health Sciences, Stellenbosch University, Stellenbosch, South Africa); Jiri Dvorak, MD, $\mathrm{PhD}$ (Spine Unit, Swiss Concussion Center and Swiss Golf Medical Center, Schulthess Clinic, Zurich, Switzerland); Carolyn A. Emery, PT, PhD (Sport Injury Prevention Research Centre, Faculty of Kinesiology, University of Calgary, Calgary, Alberta, Canada; Pediatrics and Community Health Sciences, Cumming School of Medicine, University of Calgary, Calgary, Alberta, Canada); Caroline F. Finch, PhD (School of Medical and Health Sciences, Edith Cowan University, Joondalup, Western Australia, Australia); Martin Hägglund, PT, PhD (Department of Medical and Health Sciences, Division of Physiotherapy, Linköping University, Linköping, Sweden); Astrid Junge, PhD (Medical School Hamburg, Hamburg, Germany; Swiss Concussion Centre, Schulthess Clinic, Zurich, Switzerland); Simon Kemp, MBBS, MSc (Rugby Football Union, London, UK; Department of Epidemiology and Population Health, London School of Hygiene and Tropical Medicine, London, UK); Karim M. Khan, MD, PhD (Department of Family Practice, University of British Columbia, Vancouver, British Columbia, Canada; British Journal of Sports Medicine, London, UK); Stephen W. Marshall, PhD (Injury Prevention Research Center and Department of Epidemiology at the Gillings School of Global Public Health, University of North Carolina at Chapel Hill, Chapel Hill, North Carolina, USA); Willem Meeuwisse, MD, PhD (Sport Injury Prevention Research Centre, University of Calgary, Calgary, Alberta, Canada; National Hockey League, Calgary, Alberta, Canada); Margo Mountjoy, MD, PhD (Department of Family Medicine (Sport Medicine), McMaster University, Hamilton, Ontario, Canada; FINA Bureau (Sport Medicine), Lausanne, Switzerland); John W. Orchard, MD, PhD (School of Public Health, University of Sydney, New South Wales, Sydney, Australia); Babette Pluim, MD, PhD, MPH (Department of Sports Medicine, Royal Netherlands Lawn Tennis Association, Amstelveen, the Netherlands; Amsterdam Collaboration on Health \& Safety in Sports (ACHSS), AMC/VUmc IOC Research Center of Excellence, Amsterdam, the Netherlands); Kenneth L. Quarrie, PhD (New Zealand Rugby, Wellington, New Zealand; Sports Performance Research Institute New Zealand, AUT University, Auckland, New Zealand); Bruce Reider, MD (Department of Orthopaedic 
Surgery and Rehabilitation, University of Chicago, Chicago, Illinois, USA); Martin Schwellnus, MD, PhD (Sport, Exercise Medicine and Lifestyle Research Institute (SEMLI), University of Pretoria, Hatfield, South Africa); Torbjørn Soligard, PhD (Medical and Scientific Department, International Olympic Committee, Lausanne, Switzerland; Sport Injury Prevention Research Centre, Faculty of Kinesiology, Calgary, Alberta, Canada); Keith A. Stokes, PhD (Department for Health, University of Bath, Bath, UK; Rugby Football Union, Twickenham, UK); Toomas Timpka, MD, $\mathrm{PhD}$ (Athletics Research Center, Linköping University, Linköping, Sweden; Centre for Healthcare Development, Region Östergötland, Linköping, Sweden); Evert Verhagen, PhD (Amsterdam Collaboration on Health and Safety in Sports, Department of Public and Occupational Health, Amsterdam UMC, Amsterdam, the Netherlands); Abhinav Bindra, DPhil (Athlete Commission, International Olympic Committee, Lausanne, Switzerland); Richard Budgett, MD (Medical and Scientific Department, International Olympic Committee, Lausanne, Switzerland); Lars Engebretsen, MD, PhD (Oslo Sports Trauma Research Center, Department of Sports Medicine, Norwegian School of Sport Sciences, Oslo, Norway; Medical and Scientific Department, International Olympic Committee, Lausanne, Switzerland); Uğur Erdener, MD (Medical and Scientific Department, International Olympic Committee, Lausanne, Switzerland); and Karim Chamari, PhD (Aspetar Sports Medicine and Orthopedic Hospital, Doha, Qatar).

\section{ACKNOWLEDGMENT}

The authors thank Ali Abdalla Hassan and Mohamed Abdo Badwi Ismael at Aspetar Orthopaedic and Sports Medicine Hospital for their assistance with the online survey. They acknowledge invaluable assistance from Paul Blazey and David Moher in developing and revising the STROBE-SIIS checklist.

\section{REFERENCES}

1. Ahmad CS, Dick RW, Snell E, et al. Major and Minor League Baseball hamstring injuries: epidemiologic findings from the Major League Baseball Injury Surveillance System. Am J Sports Med. 2014;42(6): 1464-1470.

2. American Spinal Injury Association. International Standards for Neurological Classification of Spinal Injury. Chicago: American Spinal Injury Association; 2019.

3. Bahr R. No injuries, but plenty of pain? On the methodology for recording overuse symptoms in sports. Br J Sports Med. 2009; 43(13):966-972.

4. Bahr R, Clarsen B, Ekstrand J. Why we should focus on the burden of injuries and illnesses, not just their incidence. Br J Sports Med. 2018; 52(16):1018-1021.

5. Bahr R, Krosshaug T. Understanding injury mechanisms: a key component of preventing injuries in sport. Br J Sports Med. 2005;39(6): 324-329.

6. Bjorneboe J, Florenes TW, Bahr R, et al. Injury surveillance in male professional football: is medical staff reporting complete and accurate? Scand J Med Sci Sports. 2011;21(5):713-720.

7. Bromley S, Drew M, Talpey S, et al. Collecting health and exposure data in Australian Olympic combat sports: feasibility study utilizing an electronic system. JMIR Hum Factors. 2018;5(4):e27.
8. Brooks JH, Fuller CW. The influence of methodological issues on the results and conclusions from epidemiological studies of sports injuries: illustrative examples. Sports Med. 2006;36(6):459-472.

9. Brooks JH, Fuller CW, Kemp SP, et al. An assessment of training volume in professional rugby union and its impact on the incidence, severity, and nature of match and training injuries. J Sports Sci. 2008; 26(8):863-873.

10. Brooks JH, Fuller CW, Kemp SP, et al. Epidemiology of injuries in English professional rugby union, part 1: match injuries. Br J Sports Med. 2005;39(10):757-766.

11. Brooks JH, Fuller CW, Kemp SP, et al. Epidemiology of injuries in English professional rugby union, part 2: training injuries. Br J Sports Med. 2005;39(10):767-775.

12. Brooks JH, Fuller CW, Kemp SP, et al. Incidence, risk, and prevention of hamstring muscle injuries in professional rugby union. Am J Sports Med. 2006;34(8):1297-1306.

13. Brophy RH, Johnston JT, Schub D, et al. Video analysis of anterior cruciate ligament tears in professional American football athletes: response. Am J Sports Med. 2018;46(14):NP73-NP74.

14. Clarsen B, Bahr R. Matching the choice of injury/illness definition to study setting, purpose and design: one size does not fit all! Br J Sports Med. 2014;48(7):510-512.

15. Clarsen B, Bahr R, Myklebust G, et al. Improved reporting of overuse injuries and health problems in sport: an update of the Oslo Sport Trauma Research Center questionnaires. Br J Sports Med. In press.

16. Clarsen B, Myklebust G, Bahr R. Development and validation of a new method for the registration of overuse injuries in sports injury epidemiology: the Oslo Sports Trauma Research Centre (OSTRC) overuse injury questionnaire. Br J Sports Med. 2013;47(8):495-502.

17. Clarsen B, Ronsen O, Myklebust G, et al. The Oslo Sports Trauma Research Center Questionnaire on Health Problems: a new approach to prospective monitoring of illness and injury in elite athletes. $\mathrm{Br} \mathrm{J}$ Sports Med. 2014;48(9):754-760.

18. Coggon D, Barker DJP, Rose G. Epidemiology for the Uninitiated. 5th ed. London: BMJ Books; 2003.

19. CONSORT Group. The CONSORT statement. 2010. http://www. consort-statement.org/. Accessed October 9, 2019.

20. Cooper DE. Video analysis of anterior cruciate ligament tears in professional American football athletes: letter to the editor. Am J Sports Med. 2018;46(14):NP73.

21. Drawer S, Fuller CW. Evaluating the level of injury in English professional football using a risk based assessment process. $\mathrm{Br} J$ Sports Med. 2002;36(6):446-451.

22. Dreyer NA, Mack CD, Anderson RB, et al. Lessons on data collection and curation from the NFL Injury Surveillance Program. Sports Health. 2019;11(5):440-445.

23. Echemendia RJ, Meeuwisse W, McCrory P, et al. The Sport Concussion Assessment Tool 5th edition (SCAT5): background and rationale. Br J Sports Med. 2017;51(11):848-850.

24. Edouard $\mathrm{P}$, Branco $\mathrm{P}$, Alonso JM, et al. Methodological quality of the injury surveillance system used in international athletics championships. J Sci Med Sport. 2016;19(12):984-989.

25. Ekegren CL, Donaldson A, Gabbe BJ, et al. Implementing injury surveillance systems alongside injury prevention programs: evaluation of an online surveillance system in a community setting. Inj Epidemiol. 2014;1(1):19.

26. Ekegren CL, Gabbe BJ, Finch CF. Sports injury surveillance systems: a review of methods and data quality. Sports Med. 2016;46(1):49-65.

27. Ekstrand J, Healy JC, Walden M, et al. Hamstring muscle injuries in professional football: the correlation of MRI findings with return to play. Br J Sports Med. 2012;46(2):112-117.

28. Endres BD, Kerr ZY, Stearns RL, et al. Epidemiology of sudden death in organized youth sports in the United States, 2007-2015. J Athl Train. 2019;54(4):349-355.

29. England Professional Rugby Injury Surveillance Project Steering Group. The England Professional Rugby Injury Surveillance Project. 2018. https://www.englandrugby.com/participation/playing/playerwelfare-rugby-safe/rugbysafe-research. Accessed October 9, 2019. 
30. European Commission. EU data protection rules. 2018. https://ec. europa.eu/commission/priorities/justice-and-fundamental-rights/ data-protection/2018-reform-eu-data-protection-rules/eu-dataprotection-rules_en. Accessed November 11, 2019.

31. Fagher K, Jacobsson J, Dahlstrom O, et al. An eHealth application of self-reported sports-related injuries and illnesses in Paralympic sport: pilot feasibility and usability study. JMIR Hum Factors. 2017;4(4):e30.

32. Field N, Cohen T, Struelens MJ, et al. Strengthening the Reporting of Molecular Epidemiology for Infectious Diseases (STROME-ID): an extension of the STROBE statement. Lancet Infect Dis. 2014;14(4):341-352.

33. Finch CF. An overview of some definitional issues for sports injury surveillance. Sports Med. 1997;24(3):157-163.

34. Finch CF, Cook J. Categorising sports injuries in epidemiological studies: the subsequent injury categorisation (SIC) model to address multiple, recurrent and exacerbation of injuries. $\mathrm{Br} J$ Sports Med. 2014;48(17):1276-1280.

35. Finch CF, Fortington LV. So you want to understand subsequent injuries better? Start by understanding the minimum data collection and reporting requirements. Br J Sports Med. 2018;52(17):1077-1078.

36. Finch CF, Goode N, Shaw L, et al. End-user experiences with two incident and injury reporting systems designed for led outdoor activities: challenges for implementation of future data systems. Inj Epidemiol. 2019;6:39.

37. Finch CF, Marshall SW. Let us stop throwing out the baby with the bathwater: towards better analysis of longitudinal injury data. $\mathrm{Br} \mathrm{J}$ Sports Med. 2016;50(12):712-715.

38. Finch CF, Mitchell DJ. A comparison of two injury surveillance systems within sports medicine clinics. J Sci Med Sport. 2002;5(4): 321-335.

39. Finch CF, Orchard JW, Twomey DM, et al. Coding OSICS sports injury diagnoses in epidemiological studies: does the background of the coder matter? Br J Sports Med. 2014;48(7):552-556.

40. Finch CF, Staines C. Guidance for sports injury surveillance: the 20year influence of the Australian Sports Injury Data Dictionary. Inj Prev. 2018;24(5):372-380.

41. Finch CF, Valuri G, Ozanne-Smith J. Injury surveillance during medical coverage of sporting events: development and testing of a standardised data collection form. J Sci Med Sport. 1999;2(1):42-56.

42. Florenes TW, Nordsletten L, Heir S, et al. Recording injuries among World Cup skiers and snowboarders: a methodological study. Scand J Med Sci Sports. 2011;21(2):196-205.

43. Fortington LV, Kucera KL, Finch CF. A call to capture fatalities in consensus statements for sports injury/illness surveillance. $\mathrm{Br} \mathrm{J}$ Sports Med. 2017;51(14):1052-1053.

44. Fortington LV, van der Worp H, van den Akker-Scheek I, et al. Reporting multiple individual injuries in studies of team ball sports: a systematic review of current practice. Sports Med. 2017;47(6):1103-1122.

45. Frost WH. Some conceptions of epidemics in general by Wade Hampton Frost. Am J Epidemiol. 1976;103(2):141-151.

46. Fuller C, Drawer S. The application of risk management in sport. Sports Med. 2004;34(6):349-356.

47. Fuller CW. Injury risk (burden), risk matrices and risk contours in team sports: a review of principles, practices and problems. Sports Med. 2018;48(7):1597-1606.

48. Fuller CW, Brooks JH, Cancea RJ, et al. Contact events in rugby union and their propensity to cause injury. $\mathrm{Br} J$ Sports Med. 2007;41: 862-867.

49. Fuller CW, Ekstrand J, Junge A, et al. Consensus statement on injury definitions and data collection procedures in studies of football (soccer) injuries. Br J Sports Med. 2006;40(3):193-201.

50. Fuller CW, Ekstrand J, Junge A, et al. Consensus statement on injury definitions and data collection procedures in studies of football (soccer) injuries. Clin J Sport Med. 2006;16(2):97-106.

51. Fuller CW, Ekstrand J, Junge A, et al. Consensus statement on injury definitions and data collection procedures in studies of football (soccer) injuries. Scand J Med Sci Sports. 2006;16(2):83-92.

52. Fuller CW, Molloy MG, Bagate $\mathrm{C}$, et al. Consensus statement on injury definitions and data collection procedures for studies of injuries in rugby union. Br J Sports Med. 2007;41(5):328-331.
53. Gabbe BJ, Finch CF, Bennell KL, et al. How valid is a self reported 12 month sports injury history? Br J Sports Med. 2003;37(6):545-547.

54. Gamage PJ, Fortington LV, Finch CF. Adaptation, translation and reliability of the Australian "Juniors Enjoying Cricket Safely" injury risk perception questionnaire for Sri Lanka. BMJ Open Sport Exerc Med. 2018;4(1):e000289.

55. Gardner AJ, Iverson GL, Williams WH, et al. A systematic review and meta-analysis of concussion in rugby union. Sports Med. 2014;44(12): 1717-1731.

56. Gordon JE. The epidemiology of accidents. Am J Public Health Nations Health. 1949;39(4):504-515.

57. Griffin LY, Agel J, Albohm MJ, et al. Noncontact anterior cruciate ligament injuries: risk factors and prevention strategies. J Am Acad Orthop Surg. 2000;8(3):141-150.

58. Haddon W Jr. Energy damage and the ten countermeasure strategies. Hum Factors. 1973;15(4):355-366.

59. Hagglund $M$, Walden $M$, Magnusson $H$, et al. Injuries affect team performance negatively in professional football: an 11-year followup of the UEFA Champions League injury study. $\mathrm{Br} J$ Sports Med. 2013;47(12):738-742.

60. Hamilton GM, Meeuwisse WH, Emery CA, et al. Subsequent injury definition, classification, and consequence. Clin J Sport Med. 2011; 21(6):508-514.

61. Harkness J, Pennell BE, Schoua-Glusberg A. Survey questionnaire translation and assessment. In: Presser S, Rothgeb JM, Couper MP, et al, eds. Methods for Testing and Evaluating Survey Questionnaires. Hoboken, New Jersey: John Wiley and Sons; 2004:453-473.

62. Holder Y, Peden M, Krug E, et al. Injury Surveillance Guidelines. Geneva: World Health Organization; 2001.

63. Institute of Social and Preventive Medicine, University of Bern. STROBE statement: Strengthening the Reporting of Observational Studies in Epidemiology. 2009. https://www.strobe-statement.org/ index.php?id=available-checklists. Accessed November 11, 2019.

64. Junge A, Engebretsen L, Alonso JM, et al. Injury surveillance in multisport events: the International Olympic Committee approach. $\mathrm{Br} J$ Sports Med. 2008;42(6):413-421.

65. King DA, Gabbett TJ, Gissane C, et al. Epidemiological studies of injuries in rugby league: suggestions for definitions, data collection and reporting methods. J Sci Med Sport. 2009;12(1):12-19.

66. Kucera KL, Fortington LV, Wolff CS, et al. Estimating the international burden of sport-related death: a review of data sources. Inj Prev. 2019;25(2):83-89.

67. Kucera KL, Marshall SW, Bell DR, et al. Validity of soccer injury data from the National Collegiate Athletic Association's Injury Surveillance System. J Athl Train. 2011;46(5):489-499.

68. Langan SM, Schmidt SA, Wing K, et al. The reporting of studies conducted using observational routinely collected health data statement for pharmacoepidemiology (RECORD-PE). BMJ. 2018;363:K3532.

69. Langley J, Brenner R. What is an injury? Inj Prev. 2004;10(2):69-71.

70. Lee TA, Pickard AS. Exposure definition and measurement. In: Velentgas P, Dreyer NA, Nourjah P, et al, eds. Developing a Protocol for Observational Comparative Effectiveness Research: A User's Guide. Rockville, Maryland: Agency for Healthcare Research and Quality; 2013:45-58.

71. Leppanen M, Pasanen K, Clarsen B, et al. Overuse injuries are prevalent in children's competitive football: a prospective study using the OSTRC overuse injury questionnaire. Br J Sports Med. 2019;53(3):165-171.

72. Malik I, Burnett S, Webster-Smith M, et al. Benefits and challenges of electronic data capture (EDC) systems versus paper case report forms. Trials. 2015;16:37.

73. Meeuwisse WH. What is the mechanism of no injury (MONI)? Clin $J$ Sport Med. 2009;19(1):1-2.

74. Meeuwisse WH, Tyreman $\mathrm{H}$, Hagel $B$, et al. A dynamic model of etiology in sport injury: the recursive nature of risk and causation. Clin $J$ Sport Med. 2007;17(3):215-219.

75. Mohtadi N. Development and validation of the quality of life outcome measure (questionnaire) for chronic anterior cruciate ligament deficiency. Am J Sports Med. 1998;26(3):350-359.

76. Moller M, Wedderkopp N, Myklebust G, et al. The SMS, Phone, and Medical Examination sports injury surveillance system is a feasible 
and valid approach to measuring handball exposure, injury occurrence, and consequences in elite youth sport. Scand J Med Sci Sports. 2018;28(4):1424-1434.

77. Moller M, Wedderkopp N, Myklebust G, et al. Validity of the SMS, Phone, and Medical Staff Examination sports injury surveillance system for time-loss and medical attention injuries in sports. Scand $J$ Med Sci Sports. 2018;28(1):252-259.

78. Mountjoy M, Junge A, Alonso JM, et al. Consensus statement on the methodology of injury and illness surveillance in FINA (aquatic sports). Br J Sports Med. 2016;50(10):590-596.

79. Murray CJ. Quantifying the burden of disease: the technical basis for disability-adjusted life years. Bull World Health Organ. 1994;72(3): 429-445.

80. Neil ER, Winkelmann ZK, Edler JR. Defining the term "overuse": an evidence-based review of sports epidemiology literature. J Athl Train. 2018;53(3):279-281.

81. Nilstad A, Bahr R, Andersen TE. Text messaging as a new method for injury registration in sports: a methodological study in elite female football. Scand J Med Sci Sports. 2014;24(1):243-249.

82. Olsen OE, Myklebust G, Engebretsen L, et al. Injury mechanisms for anterior cruciate ligament injuries in team handball: a systematic video analysis. Am J Sports Med. 2004;32(4):1002-1012.

83. Orchard J, Newman D, Stretch R, et al. Methods for injury surveillance in international cricket. J Sci Med Sport. 2005;8(1):1-14.

84. Orchard JW, Ranson C, Olivier B, et al. International consensus statement on injury surveillance in cricket: a 2016 update. Br J Sports Med. 2016;50(20):1245-1251.

85. Orchard O, Meeuwisse W, Derman W, et al. Refinement and presentation of the Calgary Sport Medicine Diagnostic Coding System (SMDSC) and the Orchard Sport Injury \& IIIness Classification System (OSIICS). Br J Sports Med. In press.

86. Pluim BM, Fuller CW, Batt ME, et al. Consensus statement on epidemiological studies of medical conditions in tennis, April 2009. Br J Sports Med. 2009;43(12):893-897.

87. Quarrie KL, Hopkins WG. Tackle injuries in professional rugby union. Am J Sports Med. 2008;36(9):1705-1716.

88. Roberts SP, Trewartha G, England M, et al. Epidemiology of time-loss injuries in English community-level rugby union. BMJ Open. 2013; 3(11):e003998.

89. Roos EM, Lohmander LS. The Knee injury and Osteoarthritis Outcome Score (KOOS): from joint injury to osteoarthritis. Health Qual Life Outcomes. 2003;1:64.

90. Roos KG, Marshall SW. Definition and usage of the term "overuse injury" in the US high school and collegiate sport epidemiology literature: a systematic review. Sports Med. 2014; 44(3):405-421.

91. Schwellnus M, Derman W, Page T, et al. Illness during the 2010 Super 14 Rugby Union tournament: a prospective study involving 22676 player days. Br J Sports Med. 2012;46(7):499-504.

92. Schwellnus M, Kipps C, Roberts WO, et al. Medical encounters (including injury and illness) at mass community-based endurance sports events: an international consensus statement on definitions and methods of data recording and reporting. $\mathrm{Br} J$ Sports Med. 2019;53(17):1048-1055.

93. Shrier I, Steele RJ. Classification systems for reinjuries: a continuing challenge. Br J Sports Med. 2014;48(18):1338-1339.

94. Soligard T, Steffen K, Palmer D, et al. Sports injury and illness incidence in the Rio de Janeiro 2016 Olympic Summer Games: a prospective study of 11274 athletes from 207 countries. Br J Sports Med. 2017;51(17):1265-1271.

95. Soligard T, Steffen K, Palmer-Green D, et al. Sports injuries and illnesses in the Sochi 2014 Olympic Winter Games. Br J Sports Med. 2015;49(7):441-447.

96. Soomro N, Chhaya M, Soomro M, et al. Design, development, and evaluation of an injury surveillance app for cricket: protocol and qualitative study. JMIR mHealth uHealth. 2019;7(1):e10978.
97. Tabben M, Whiteley $\mathrm{R}$, Wik EH, et al. Methods may matter in injury surveillance: "how" may be more important than "what, when or why". Biol Sport. 2020;37(1):3-5.

98. Timpka T, Alonso JM, Jacobsson J, et al. Injury and illness definitions and data collection procedures for use in epidemiological studies in athletics (track and field): consensus statement. $\mathrm{Br} J$ Sports Med. 2014;48(7):483-490.

99. Timpka T, Jacobsson J, Bickenbach $\mathrm{J}$, et al. What is a sports injury? Sports Med. 2014;44(4):423-428.

100. Toohey LA, Drew MK, Fortington LV, et al. Comparison of subsequent injury categorisation (SIC) models and their application in a sporting population. Inj Epidemiol. 2019;6:9.

101. Toohey LA, Drew MK, Fortington LV, et al. An updated subsequent injury categorisation model (SIC-2.0): data-driven categorisation of subsequent injuries in sport. Sports Med. 2018;48(9):2199-2210.

102. Turner M, Fuller CW, Egan D, et al. European consensus on epidemiological studies of injuries in the thoroughbred horse racing industry. Br J Sports Med. 2012;46(10):704-708.

103. van Dyk N, van der Made AD, Timmins RG, et al. There is strength in numbers for muscle injuries: it is time to establish an international collaborative registry. Br J Sports Med. 2018;52(19):1228-1229.

104. van Mechelen W. The severity of sports injuries. Sports Med. 1997; 24(3):176-180.

105. van Mechelen W. Sports injury surveillance systems: "one size fits all"? Sports Med. 1997;24(3):164-168.

106. von Elm E, Altman DG, Egger M, et al. Strengthening the Reporting of Observational Studies in Epidemiology (STROBE) statement: guidelines for reporting observational studies. BMJ. 2007; 335(7624):806-808.

107. Waller JA. Injury Control: A Guide to the Causes and Prevention of Trauma. Lexington, Massachusetts: Lexington Books; 1985.

108. Weir A, Brukner P, Delahunt E, et al. Doha agreement meeting on terminology and definitions in groin pain in athletes. Br J Sports Med. 2015;49(12):768-774.

109. Wik EH, Materne O, Chamari K, et al. Involving research-invested clinicians in data collection affects injury incidence in youth football. Scand J Med Sci Sports. 2019;29(7):1031-1039.

110. Williams S, Trewartha G, Kemp SP, et al. Time loss injuries compromise team success in elite rugby union: a 7-year prospective study. Br J Sports Med. 2016;50(11):651-656.

111. World Health Organization. International Classification of Diseases, 11th Revision. 2018. https://www.who.int/classifications/icd/en/. Accessed November 11, 2019.

112. World Health Organization. International Classification of External Causes of Injury (ICECI). 2003. https://www.who.int/classifications/ icd/adaptations/iceci/en/. Accessed November 11, 2019.

113. World Health Organization. International Classification of Functioning, Disability and Health. 2018. https://www.who.int/classifications/ icf/en/. Accessed December 5, 2019

114. World Health Organization. Preamble to the Constitution of the World Health Organization as Adopted by the International Health Conference. New York: World Health Organization; 1946.

115. World Medical Association. WMA Declaration of Helsinki: ethical principles for medical research involving human subjects. 2013. https://www.wma.net/policies-post/wma-declaration-of-helsinkiethical-principles-for-medical-research-involving-human-subjects/. Accessed October 9, 2019.

116. World Medical Association. WMA Declaration of Taipei on ethical considerations regarding health databases and biobanks. 2016. https://www.wma.net/policies-post/wma-declaration-of-taipei-onethical-considerations-regarding-health-databases-and-biobanks/. Accessed October 9, 2019.

117. Yeomans C, Kenny IC, Cahalan R, et al. The design, development, implementation and evaluation of IRISweb: a rugbyspecific web-based injury surveillance system. Phys Ther Sport. 2019;35:79-88. 


\section{APPENDIX 1}

\section{Case Study: Tackle Injuries to Ball Carriers in Rugby}

\section{Data Set}

A study was conducted in which video records of every tackle that occurred in 434 professional rugby matches were coded on a range of dimensions, including the location on the body at which the tackler(s) contacted the ball carrier ("tackle height"). ${ }^{87}$ The information in the table has been restricted to that from 43,366 tackles in which a single tackler tackled a ball carrier (ie, the 100 tackle events per match that met this criteria). For the purposes of the example below, an injury is defined as "any injury sustained by a ball carrier during a rugby tackle that required them to be removed from the field of play for the remainder of the match."

\section{Different Denominators: Different Perspectives on Risk}

Rates of injury have been presented in Table A1 as "per 10,000 tackles" and "per 10,000 player-hours." If data were reported using only the time-based denominator, as has been the case in most studies of sports injury epidemiology, the conclusion drawn would be that "high" and "middle" tackles are those that carry the greatest risk to ball carriers. When the relative frequency of the tackles is considered, and the rates are presented on a "per 10,000 tackles" basis, head/neck tackles place ball carriers at the greatest risk of injuries when they occur.

The different perspectives provided by per-event and per-time denominators can be helpful in identifying injury prevention priorities. If the overall risk of injuries was considered unacceptably high by those responsible for managing the risks in the sport, then reducing the numbers of the
TABLE A1

Injury Rates to Ball Carriers in Rugby Tackles ${ }^{a}$

\begin{tabular}{|c|c|c|c|c|}
\hline \multirow[b]{2}{*}{$\begin{array}{l}\text { Tackle } \\
\text { Height }\end{array}$} & \multirow[b]{2}{*}{$\begin{array}{l}\text { Tackles } \\
\text { per } \\
\text { Match }\end{array}$} & \multicolumn{3}{|c|}{$\begin{array}{l}\text { Injuries Requiring Player to Be } \\
\text { Removed From Match }\end{array}$} \\
\hline & & $\begin{array}{c}\text { Per } \\
10,000 \\
\text { Tackles }\end{array}$ & $\begin{array}{c}\text { Per } \\
10,000 \\
\text { Player-Hours }\end{array}$ & $\begin{array}{l}\text { Percentage } \\
\text { of Injuries } \\
\text { per } 10,000 \\
\text { Player-Hours }\end{array}$ \\
\hline Head/neck & $4 \pm 2$ & $43(23-79)$ & $4(2-8)$ & $13(7-23)$ \\
\hline $\begin{array}{l}\text { High } \\
\text { Middle }\end{array}$ & $\begin{array}{l}37 \pm 10 \\
44 \pm 9\end{array}$ & $\begin{array}{r}12(8-17) \\
9(6-13)\end{array}$ & $\begin{array}{l}11(8-16) \\
10(7-15)\end{array}$ & $\begin{array}{l}36(26-47) \\
32(23-43)\end{array}$ \\
\hline Low & $15 \pm 5$ & $16(9-26)$ & $6(3-10)$ & $19(12-29)$ \\
\hline
\end{tabular}

${ }^{a}$ Rates are expressed via event- and time-based denominators. Data are shown as mean \pm standard deviation or mean (range).

most common tackles in the game would have the greatest effect; together, high and middle tackles account for over two-thirds of all tackle injuries requiring ball carriers to be removed from the pitch. Reducing the numbers of such tackles, or the characteristics of them, would probably require major changes to the sport of rugby. If, however, the overall degree of risk were considered acceptable, then focusing on decreasing the number of head and neck tackles would have a modest effect on overall injury rates but reduce the occurrence of a particularly risky element of the sport (note: head/neck tackles are not permitted within the laws of rugby, but sometimes occur).

The types of exposure measures that can form the basis of risk statistics are presented in Table A2, along with a range of risk measures that have been reported in studies of team sports injury epidemiology. The examples are taken from the same study discussed above.

TABLE A2

A Range of Exposure and Risk Measures Derived From Injury Surveillance Data ${ }^{a}$

\begin{tabular}{|c|c|c|c|c|}
\hline Statistic & Value & Calculation & Explanation & Comment \\
\hline \multicolumn{5}{|l|}{ Injury statistics } \\
\hline $\begin{array}{l}\text { No. of injuries (carrier } \\
\text { injury replacements } \\
\text { in } 434 \text { matches) }\end{array}$ & 53 & Nil & $\begin{array}{l}\text { Count of the number of } \\
\text { tackler injuries requiring } \\
\text { the injured player to be } \\
\text { replaced observed in } 434 \\
\text { matches }\end{array}$ & $\begin{array}{l}\text { The "numerator" used for calculating the } \\
\text { rate of tackler replacement injuries per } \\
\text { unit of time or per tackle. Absolute } \\
\text { numbers and costs of injuries are of } \\
\text { interest to risk managers, especially } \\
\text { when provided in parallel with rates. }\end{array}$ \\
\hline \multicolumn{5}{|l|}{ Exposure measures } \\
\hline $\begin{array}{l}\text { Player-hours in } 434 \\
\text { matches }\end{array}$ & 17,360 & $30 \times 579$ & $\begin{array}{l}30 \text { players ( } 15 \text { from each } \\
\text { team) multiplied by } 579 \\
\text { (hours of play in } 434 \\
\text { matches of } 80 \text { minutes' } \\
\text { duration) }\end{array}$ & $\begin{array}{l}\text { This number provides a "time-window" } \\
\text { denominator. Usually, it is assumed } \\
\text { that time lost for yellow and red cards, } \\
\text { or time gained for "extra time," is } \\
\text { negligible and is ignored. }\end{array}$ \\
\hline
\end{tabular}


Table A2 (continued)

\begin{tabular}{|c|c|c|c|c|}
\hline Statistic & Value & Calculation & Explanation & Comment \\
\hline $\begin{array}{l}\text { No. of single-tackler } \\
\text { tackle events in } 434 \\
\text { matches }\end{array}$ & 43,366 & Nil & $\begin{array}{l}\text { All tackles in } 434 \text { matches } \\
\text { were coded, regardless of } \\
\text { whether they resulted in } \\
\text { injury }\end{array}$ & $\begin{array}{l}\text { This number forms an "event-based" } \\
\text { denominator. }\end{array}$ \\
\hline $\begin{array}{l}\text { No. of players who } \\
\text { appeared in the } 434 \\
\text { matches }\end{array}$ & 1403 & Nil & & $\begin{array}{l}\text { This is a count of the size of the cohort } \\
\text { across the entire study period. It is used } \\
\text { as the denominator for calculating } \\
\text { injury risk. }\end{array}$ \\
\hline $\begin{array}{l}\text { No. of full player } \\
\text { matches }\end{array}$ & 13,020 & $30 \times 434$ & $\begin{array}{l}30 \text { players ( } 15 \text { from each } \\
\text { team) multiplied by } 434 \\
\text { matches }\end{array}$ & $\begin{array}{l}\text { This number provides a "per-match" } \\
\text { denominator. }\end{array}$ \\
\hline $\begin{array}{l}\text { No. of athlete- } \\
\text { exposures (athlete- } \\
\text { participations) }\end{array}$ & 17,685 & Nil & $\begin{array}{l}\text { Count of the number of } \\
\text { players who took the field } \\
\text { over } 434 \text { matches (players } \\
\text { can be substituted for } \\
\text { tactical purposes or } \\
\text { replaced due to injury) }\end{array}$ & $\begin{array}{l}\text { The similarity to the number of player- } \\
\text { hours is coincidental. There are } 40 \\
\text { hours of player time per match, and the } \\
\text { average number of athlete-exposures } \\
\text { per match over this series of matches } \\
\text { was } 40.8 \text {. }\end{array}$ \\
\hline \multicolumn{5}{|l|}{ Risk measures } \\
\hline $\begin{array}{l}\text { Period prevalence } \\
\text { (percentage of cohort } \\
\text { injured) }\end{array}$ & $3 \%$ & $(48 / 1403) \times 100$ & $\begin{array}{l}\text { Percentage of people who } \\
\text { appeared in matches who } \\
\text { were replaced }\end{array}$ & $\begin{array}{l}\text { Often reported as the "risk per season" or } \\
\text { "risk per year." It cannot be easily used } \\
\text { to compare between activities if the } \\
\text { duration of surveillance varies from } \\
\text { activity to activity. The longer the } \\
\text { surveillance period, the higher the risk } \\
\text { will appear to be for closed cohorts. }\end{array}$ \\
\hline $\begin{array}{l}\text { Injuries per } 1000 \\
\text { player-hours }\end{array}$ & 3.1 & $(53 / 17,360) \times 1000$ & $\begin{array}{l}\text { Number of injuries is divided } \\
\text { by the number of hours of } \\
\text { player exposure and } \\
\text { multiplied by a scaling } \\
\text { factor (eg, } 1000,10,000 \text { ) to } \\
\text { provide a rate that is } \\
\text { convenient to work with } \\
\text { (eg, numbers in the range } \\
\text { of } 1 \text { to } 1000 \text { rather than } \\
\text { numbers }<0 \text { or }>1000 \text { ) }\end{array}$ & $\begin{array}{l}\text { The most commonly reported metric of } \\
\text { injury rates in studies of rugby injury } \\
\text { epidemiology has been the rate of } \\
\text { injuries per } 1000 \text { player-hours. This } \\
\text { convention is endorsed in the consensus } \\
\text { statement by Fuller et al. }{ }^{52} \text { It is } \\
\text { relatively simple to estimate based on } \\
\text { the number of matches played. } \\
\text { Comparisons of incidence rates between } \\
\text { activities or within activities over time } \\
\text { based on this denominator require the } \\
\text { assumption that the number and } \\
\text { characteristics of energy transfers to } \\
\text { which participants are exposed remain } \\
\text { relatively constant per unit of exposure } \\
\text { time. }\end{array}$ \\
\hline $\begin{array}{l}\text { Injuries per } 1000 \\
\text { matches }\end{array}$ & 122 & $(53 / 434) \times 1000$ & $\begin{array}{l}\text { Rate of tackler replacements } \\
\text { per rugby union match } \\
\text { multiplied by } 1000 ; \text { rate } \\
\text { per match multiplied by a } \\
\text { factor that provides a } \\
\text { convenient interpretation } \\
(0.12 \text { carrier replacement } \\
\text { injuries per match, } 12.2 \\
\text { per } 100 \text { matches, } 122 \text { per } \\
1000 \text { matches, etc) }\end{array}$ & $\begin{array}{l}\text { Ignores the number of players and match } \\
\text { duration and provides an estimate of the } \\
\text { number of injuries that an observer } \\
\text { would expect to see if they watched } 1000 \\
\text { matches. Not useful for comparing } \\
\text { incidence rates between activities of } \\
\text { differing durations or numbers of } \\
\text { participants. }\end{array}$ \\
\hline
\end{tabular}


Table A2 (continued)

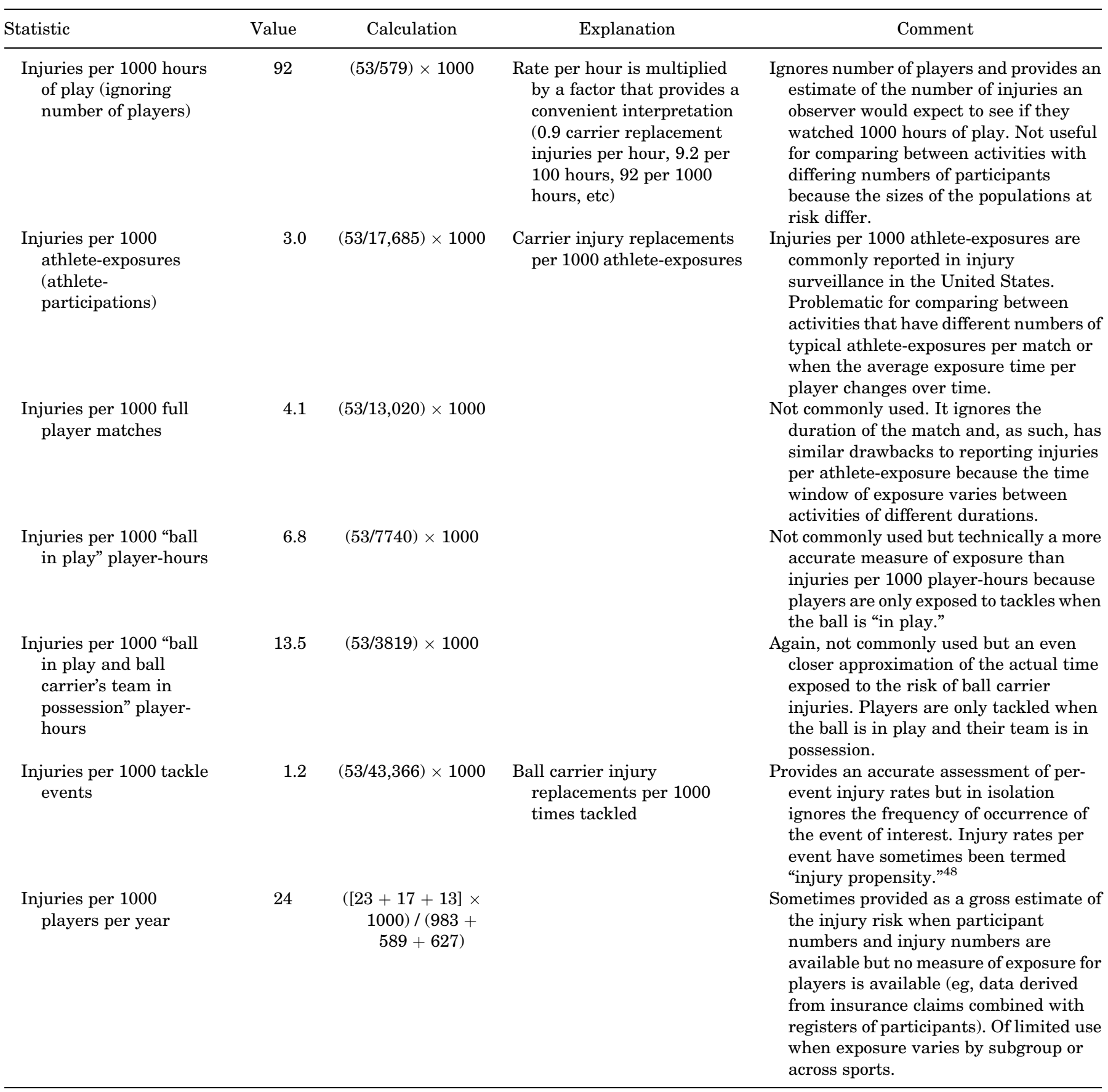

\footnotetext{
${ }^{a}$ Examples from a study of rugby tackle injuries. ${ }^{87}$
} 


\section{APPENDIX 2A}

\section{Daily Medical Report on Injuries and IIInesses}

Country:

Form completed by: Name:
Date of report:

Contact details:

Please report: (1) All sport injuries and (2) all illnesses of your athletes newly incurred, recurrent or an exacerbation of an underlying stable injury/illness during the <name of the championship> regardless of the consequences with respect to absence from competition or training. The information provided will be treated strictly confidential.

1. Injury - Example

Definitions and codes (see reverse)

\begin{tabular}{|c|c|c|c|c|c|c|c|c|c|}
\hline $\begin{array}{c}\text { age } \\
22\end{array}$ & \multicolumn{2}{|c|}{$\begin{array}{c}\text { gender } \\
\text { male / female }\end{array}$} & $\begin{array}{c}\text { sport and event } \\
\text { decathlon }\end{array}$ & $\begin{array}{c}\text { date of injury } \\
\text { 21. July }\end{array}$ & $\begin{array}{l}\text { competition / training } \\
\text { sprint competition }\end{array}$ & $\begin{array}{c}\text { code } \\
2\end{array}$ & \multicolumn{2}{|c|}{$\begin{array}{c}\text { onset code } \\
1\end{array}$} & \multirow{2}{*}{$\begin{array}{c}\text { new code } \\
1 \\
\text { duration } \\
28 \text { days }\end{array}$} \\
\hline $\begin{array}{l}\text { injury } r \\
\text { slippe }\end{array}$ & $\begin{array}{l}\text { chanism } \\
\text { and fell }\end{array}$ & $\begin{array}{c}\text { code } \\
5\end{array}$ & $\begin{array}{c}\text { injured body region } \\
\text { ankle }\end{array}$ & $\begin{array}{c}\text { code } \\
17\end{array}$ & $\begin{array}{l}\text { injury type } \\
\text { sprain }\end{array}$ & & $\begin{array}{c}\text { code } \\
10\end{array}$ & $\begin{array}{l}\text { time-loss } \\
\text { no/yes }\end{array}$ & \\
\hline
\end{tabular}

\begin{tabular}{|c|c|c|c|c|c|c|c|c|c|c|}
\hline age & \multicolumn{2}{|c|}{$\begin{array}{c}\text { gender } \\
\text { male / female }\end{array}$} & sport and event & \multicolumn{2}{|c|}{ date of injury } & competition / training & code & \multicolumn{2}{|c|}{ onset code } & new code \\
\hline \multicolumn{2}{|c|}{ injury mechanism } & code & \multicolumn{2}{|c|}{ injured body region } & code & injury type & & code & $\begin{array}{l}\text { time-loss } \\
\text { no / yes }\end{array}$ & $\begin{array}{r}\text { duration } \\
\text { days }\end{array}$ \\
\hline age & \multicolumn{2}{|c|}{$\begin{array}{c}\text { gender } \\
\text { male / female }\end{array}$} & sport and event & \multicolumn{2}{|c|}{ date of injury } & competition / training & code & \multicolumn{2}{|c|}{ onset code } & new code \\
\hline \multicolumn{2}{|c|}{ injury mechanism } & code & \multicolumn{2}{|c|}{ injured body region } & code & injury type & & code & $\begin{array}{l}\text { time-loss } \\
\text { no/yes }\end{array}$ & $\begin{array}{r}\text { duration } \\
\text { days }\end{array}$ \\
\hline age & \multicolumn{2}{|c|}{$\begin{array}{c}\text { gender } \\
\text { male / female }\end{array}$} & sport and event & \multicolumn{2}{|c|}{ date of injury } & competition / training & code & \multicolumn{2}{|c|}{ onset code } & new code \\
\hline \multicolumn{2}{|c|}{ injury mechanism } & code & \multicolumn{2}{|c|}{ injured body region } & code & injury type & & code & $\begin{array}{l}\text { time-loss } \\
\text { no/yes }\end{array}$ & $\begin{array}{r}\text { duration } \\
\text { days }\end{array}$ \\
\hline age & \multicolumn{2}{|c|}{$\begin{array}{c}\text { gender } \\
\text { male / female }\end{array}$} & sport and event & \multicolumn{2}{|c|}{ date of injury } & competition / training & code & \multicolumn{2}{|c|}{ onset code } & new code \\
\hline \multicolumn{2}{|c|}{ injury mechanism } & code & \multicolumn{2}{|c|}{ injured body region } & code & injury type & & code & $\begin{array}{l}\text { time-loss } \\
\text { no / yes }\end{array}$ & $\begin{array}{r}\text { duration } \\
\text { days }\end{array}$ \\
\hline
\end{tabular}

2. IIIness - Example

\begin{tabular}{|c|c|c|c|c|c|c|}
\hline $\begin{array}{r}\text { age } \\
27\end{array}$ & $\begin{array}{c}\text { gender } \\
\text { male /female }\end{array}$ & $\begin{array}{l}\text { sport and event } \\
\text { athletics, pole vault }\end{array}$ & $\begin{array}{l}\text { date of onset } \\
24^{\text {th }} \text { July }\end{array}$ & \multicolumn{2}{|l|}{$\begin{array}{l}\text { organ system / region } \\
\text { respiratory system }\end{array}$} & $\begin{array}{c}\text { code } \\
13\end{array}$ \\
\hline \multirow{2}{*}{\multicolumn{3}{|c|}{$\begin{array}{l}\text { aetiology } \\
\text { Environmental - not exercise related }\end{array}$}} & code & new, recurrent or exacerbation code & time-loss & duration \\
\hline & & & 3 & 1 & $\mathrm{no} /$ yes & 2 days \\
\hline
\end{tabular}

\begin{tabular}{|c|c|c|c|c|c|c|}
\hline age & gender & sport and event & date of onset & \multicolumn{2}{|l|}{ organ system / region } & code \\
\hline \multicolumn{3}{|l|}{ aetiology } & code & new, recurrent or exacerbation code & $\begin{array}{l}\text { time-loss } \\
\text { no / yes }\end{array}$ & $\begin{array}{r}\text { duration } \\
\text { days }\end{array}$ \\
\hline age & $\begin{array}{c}\text { gender } \\
\text { male / female }\end{array}$ & sport and event & date of onset & \multicolumn{2}{|l|}{ organ system / region } & code \\
\hline \multicolumn{3}{|l|}{ aetiology } & code & new, recurrent or exacerbation code & $\begin{array}{l}\text { time-loss } \\
\text { no / yes }\end{array}$ & $\begin{array}{r}\text { duration } \\
\text { days }\end{array}$ \\
\hline age & $\begin{array}{c}\text { gender } \\
\text { male / female }\end{array}$ & sport and event & date of onset & \multicolumn{2}{|l|}{ organ system / region } & code \\
\hline \multicolumn{3}{|l|}{ aetiology } & code & new, recurrent or exacerbation code & $\begin{array}{l}\text { time-loss } \\
\text { no / yes }\end{array}$ & $\begin{array}{r}\text { duration } \\
\text { days }\end{array}$ \\
\hline age & $\begin{array}{c}\text { gender } \\
\text { male / female }\end{array}$ & sport and event & date of onset & \multicolumn{2}{|l|}{ organ system / region } & code \\
\hline \multicolumn{3}{|l|}{ aetiology } & code & new, recurrent or exacerbation code & $\begin{array}{l}\text { time-loss } \\
\text { no / yes }\end{array}$ & $\begin{array}{r}\text { duration } \\
\text { days }\end{array}$ \\
\hline
\end{tabular}

If space is not sufficient to report all injuries or illnesses, please use additional forms.

$\square$ no new injury or illness in any athlete of our team today 


\section{Definitions and codes}

For injuries (defined as tissue damage or other derangement of normal physical function due to participation in sports, resulting from rapid or repetitive transfer of kinetic energy)

\section{Competition or training}

1 competition, please specify event

Mode of onset

1 sudden after acute trauma

Injury mechanism

1 no identifiable single event

(repetitive transfer of energy, overuse)

2 acute non-contact trauma

Injured body region

1 head / face

2 neck / cervical spine

3 chest (incl. chest organs)

4 thoracic spine / upper back

5 lumbar-sacral spine / buttock

6 abdomen (incl. abdominal organs)

Injury type

1 concussion / brain injury

2 spinal cord injury

3 peripheral nerve injury

4 bone fracture

5 bone stress injury

6 bone contusion

7 avascular necrosis

8 physis injury

9 cartilage injury
2 training

2 sudden but no acute trauma

3 direct contact with another athlete

4 following contact with another athlete (e.g. fall after a push)

7 shoulder

8 upper arm

9 elbow

10 forearm

11 wrist

12 hand

10 joint sprain / ligament tear

11 chronic instability

12 tendon rupture

13 tendinopathy

14 muscle strain / rupture / tear

15 muscle contusion

16 muscle compartment syndrome

17 laceration

18 abrasion
3 peri-competition activities

(e.g. warm-up, cool-down)

3 gradual

4 mixed

direct contact with an object (e.g. ball, wall, ground, i.e. slipped and fell)

6 following contact with an object

13 hip / groin

14 thigh

15 knee

16 lower leg / Achilles tendon

17 ankle

18 foot

19 contusion / bruise (superficial)

20 arthritis

21 bursitis

22 synovitis

23 vascular damage

24 stump injury

25 internal organ trauma

26 unknown, or not specified

For illnesses (defined as a complaint or disorder not related to injury)

Organ system

1 cardiovascular

2 dermatological

3 dental

4 endocrinology

5 gastrointestinal

Aetiology

1 allergic

2 environmental - exercise-related

3 environmental - non-exercise

4 immunological/inflammatory
6 genitourinary

7 hematologic

8 musculoskeletal

9 neurological

10 ophthalmological

5 infection

6 neoplasm

7 metabolic/nutritional

8 thrombotic/haemorrhagic
11 otological

12 psychiatric/psychological

13 respiratory system

14 thermoregulatory system

15 unknown, or not specified

9 degenerative or chronic condition 10 developmental anomaly

11 drug-related/poisoning

12 unknown, or not specified

\section{For injuries and illnesses}

Sport and event

Please report the sport (e.g. athletics) AND specify the event (e.g. pole vault) if applicable.

New, recurrent or exacerbation

1 newly incurred during the championships

2 recurrent after full recovery and return-to-sport

3 exacerbation of a stable (not recovered) condition 4 unknown, or not specified

Time-loss in sport due to injury or illness

no athlete continues to train or compete, even if not at usual level (duration, intensity, performance)

yes athlete did not finish the training or competition when the injury occurred $O R$ could not participate in sport later

Duration of impaired participation/ limited performance in sport due to injury or illness (in days)

Please provide an estimate of the number of days that the athlete will not be able to undertake his/her normal training or will not be able to compete as usual, counting the day after the onset of the injury/illness as day 1.

If an athlete is not expected to return to sport after the injury or illness, please state the reason: $F=$ fatality, $P=$ permanent disability, OR=reasons. 


\section{APPENDIX 2B}

\section{Medical Report of Injury or IIIness}

Date of report:

Team:

Athlete identification:

Date of onset:

\section{For injury}

$\begin{array}{lcc}\text { Competition or training } & \\ \square \text { competition } & \square \text { training } & \square \text { peri-competition activities } \\ \text { (e.g. warm-up, cool-down) }\end{array}$

Injury mechanism (each category might have subcategories based on the purpose of the surveillance)
$\square$ no identifiable single event
$\square$ direct contact with another athlete
$\square$ direct contact with an object
$\square$ non-contact trauma
$\square$ following contact with another athlete
$\square$ following contact with an object

Injured body region (each category might have subcategories based on the purpose of the surveillance)
$\square$ head
$\square$ shoulder
$\square$ hip / groin
$\square$ neck / cervical spine
$\square$ upper arm
$\square$ thigh
$\square$ chest (incl. chest organs)
$\square$ elbow
$\square$ knee
$\square$ thoracic spine / upper back
$\square$ forearm
$\square$ lower leg / Achilles tendon
$\square$ lumbar-sacral spine / buttock
$\square$ wrist
$\square$ ankle
$\square$ abdomen (incl. abdominal organs)
$\square$ hand
$\square$ foot

Injury type

$\square$ concussion / brain injury

$\square$ spinal cord injury

$\square$ peripheral nerve injury

$\square$ bone fracture

$\square$ bone stress injury

$\square$ bone contusion

$\square$ avascular necrosis

$\square$ physis injury

$\square$ cartilage injury

$\square$ joint sprain / ligament tear
$\square$ chronic instability
$\square$ tendon rupture
$\square$ tendinopathy
$\square$ muscle strain / rupture / tear
$\square$ muscle contusion
$\square$ muscle compartment syndrome
$\square$ laceration
$\square$ abrasion

$\square$ contusion / bruise (superficial)

$\square$ arthritis

$\square$ bursitis

$\square$ synovitis

$\square$ vascular damage

$\square$ stump injury

$\square$ internal organ trauma

$\square$ unknown, or not specified

\section{For illness}

\section{Organ system \\ $\square$ cardiovascular \\ $\square$ dermatological \\ $\square$ dental \\ $\square$ endocrinology \\ $\square$ gastrointestinal}

Aetiology

$\square$ allergic

$\square$ environmental - exercise-related

$\square$ environmental - non-exercise

$\square$ immunological / inflammatory

\section{For injury and illness}

New, recurrent or exacerbation

$\square$ new $\quad \square$ recurrent after full recovery and return-to-sport

$\square$ exacerbation of a stable (not recovered) condition

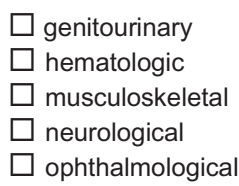

$\square$ infectious disease

$\square$ neoplasm

$\square$ metabolic / nutritional

$\square$ vascular

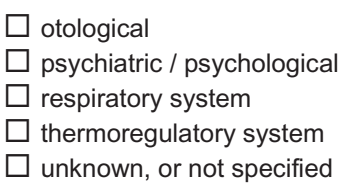

degenerative or chronic condition

$\square$ developmental anomaly

$\square$ drug-related / poisoning

$\square$ unknown, or not specified

Time-loss in sport due to injury / illness

$\square$ no $\quad \square$ yes

Date of full return to normal training and competition (dd/mm/yy)

No return to sport possible: $\square$ fatality

$\square$ permanent disability

$\square$ other reasons 


\section{APPENDIX 3}

\section{Strobe-SIIS (Sports Injury and IIIness Surveillance) Statement 1.0}

Checklist of Items for Reporting Observational Studies on Injury and Illness in Sports ${ }^{a}$

\begin{tabular}{lrr}
\hline & & Source of Rationale for Item From \\
Recommendation From & Consensus Statement and Where to \\
Item & STROBE Statement & Find Further Details
\end{tabular}

(1) Title and abstract

Introduction

(2) Background/rationale

(3) Objectives

Methods

(4) Study design

(5) Setting (a) Indicate the study's design with a commonly used term in the title or abstract

(b) Provide in the abstract an informative and balanced summary of what was done and what was found

Explain the scientific background and rationale for the investigation being reported

State specific objectives, including any prespecified hypotheses

Describe the setting, locations, and relevant dates, including periods of recruitment, exposure, follow-up, and data collection
SIIS 3.1: State whether study was registered. Identify the registration number and database used

SIIS 3.2: State the specific purpose of the study (eg, to describe the injury burden associated with Olympic-level rowing)

SIIS 4.1: Clearly specify which health problems are being observed

SIIS 4.2: State explicitly which approach was used to record the health problem data, including all outcome measures or tools

SIIS 4.3: State explicitly which coding system was used to classify the health problems (eg, OSIICS, SMDCS, ICD, etc)

SIIS 4.4: Where relevant, clearly describe how athletes were categorized. Variables to consider could include the type of athlete and/or sport, environment in which the sport occurs (eg, type of course or playing area), the typical duration of the sport, the degree of physical contact permitted in the sport, and the equipment permitted

SIIS 3.1: "Reporting guidelines: STROBE Sports Injury and Illness Surveillance (STROBESIIS)"

SIIS 3.2: Throughout consensus statement

SIIS 4.1: "Defining and classifying health problems"

SIIS 4.2: "Data collection methods" SIIS 4.3: "Classifying sports injury and illness diagnoses"

SIIS 4.4: "Study population characteristics"

SIIS 5.1: Describe the location, level
of play, dates of observation, and data collection methods (ie, who, what, where)

SIIS 5.2: Specify the dates of the surveillance period and how the data were handled when the study covered more than 1 season/calendar year

SIIS 5.3: Define whether the health problem data were collected prospectively or retrospectively
SIIS 5.1: "Study population characteristics"

SIIS 5.2: "Capturing and reporting athlete-exposure"

SIIS 5.3: "Capturing and reporting athlete-exposure" and "Data collection methods" 
(continued)

Item

(6) Participants

(7) Variables

(8) Data sources/ measurement ${ }^{b}$

\section{Recommendation From} STROBE Statement

(a) Cohort study: give the eligibility criteria and the sources and methods of selection of participants. Describe the methods of follow-up

Case-control study: give the eligibility criteria and the sources and methods of case ascertainment and control selection. Give the rationale for the choice of cases and controls

Cross-sectional study: give the eligibility criteria and the sources and methods of selection of participants

(b) Cohort study: for matched studies, give matching criteria and the number of exposed and unexposed participants

Case-control study: for matched studies, give matching criteria and the number of controls per case

Clearly define all outcomes, exposures, predictors, potential confounders, and effect modifiers. Give the diagnostic criteria, if applicable

For each variable of interest, give sources of data and details of methods of assessment (measurement). Describe comparability of assessment methods if there is more than 1 group

Source of Rationale for Item From Consensus Statement and Where to Find Further Details

SIIS 6.1: Define the population of athletes as well as describe how they were selected and recruited
SIIS 6.1: "Data collection methods" and "Study population characteristics"
SIIS 7.1: Justify why you measured your primary and secondary outcomes of interest in the specific way chosen

SIIS 7.2: Describe the method for identifying the health problem outcome of interest

SIIS 8.1: Specify who collected/ reported the data for the study and their qualifications (eg, qualified doctor, data analyst, etc)

SIIS 8.2: Specify who coded the data for the study and their qualifications (eg, qualified doctor, data analyst, etc; in many instances, this will not be the same as in SIIS 8.1)

SIIS 8.3: Specify the direct methods used to collect the data and the use of physical documents or electronic tools (if extracting information from existing sources, specify the data source)

SIIS 8.4: Specify the timing of and window for data collection (eg, day health problem occurred or following day). Specify the frequency of data collection (eg, daily, weekly, monthly)

SIIS 8.5: Report the duration of surveillance (eg, tournament, season, whole year, playing career)
SIIS 7.1: "Defining and classifying health problems"

SIIS 7.2: "Defining and classifying health problems"

SIIS 8.1: "Classifying sports injury and illness diagnoses" and "Data collection methods"

SIIS 8.2: "Classifying sports injury and illness diagnoses"

SIIS 8.3: "Data collection methods"

SIIS 8.4: "Relationship to sports activity" and "Capturing and reporting athlete-exposure" SIIS 8.5: "Relationship to sports activity" and "Capturing and reporting athlete-exposure" 


\begin{tabular}{lcc}
\hline & & Source of Rationale for Item From \\
Item & Recommendation From & Consus Statement and Where to \\
STROBE Statement & STROBE-SIIS Extension & Find Further Details \\
\hline
\end{tabular}

\section{(9) Bias}

(10) Study size

(11) Quantitative variables

(12) Statistical methods

\section{Describe any efforts to address potential sources of bias}

Explain how the study size was arrived at

Explain how quantitative variables were handled in the analyses. If applicable, describe which groupings were chosen and why

(a) Describe all the statistical methods, including those used to control for confounding

(b) Describe any methods used to examine subgroups and interactions

(c) Explain how missing data were addressed

(d) Cohort study: if applicable, explain how loss to follow-up was addressed

Case-control study: if applicable, explain how matching of cases and controls was addressed

Cross-sectional study: if applicable, describe analytical methods taking account of sampling strategy

(e) Describe any sensitivity analyses
SIIS 9.1: Clearly report any validation or reliability assessment of the data collection tools

SIIS 9.2: Formally acknowledge any potential biases associated with the data collection method (eg, self-report, recall bias, reporting by nonmedically trained staff, etc)

SIIS 11.1: Explain in detail how multiple injuries/illness episodes are handled both in individual athletes and across athletes/ surveillance periods

SIIS 11.2: Specify how injury severity was calculated

SIIS 12.1: Specify how the exposure to risk has been adjusted for and specify units (eg, per participant, per athlete-exposure, etc)

SIIS 12.2: Specify how relevant risk measures (incidence, prevalence, etc) were calculated

SIIS 12.3: When relevant to the study aim, specify how the injury burden was calculated and analyzed

SIIS 12.4: For studies reporting multiple health problems, state clearly how these were handled (eg, time to the first injury only, ignoring subsequent return to play and reinjuries, or modeling of all injuries)

SIIS 12.5: Explain how/if athletes not included at outset (eg, those already injured) were handled in the analyses

SIIS 12.6: In longitudinal studies, it is particularly important to explain how athlete follow-up has been managed. For example, what happened if a player was trasferred to another team or has been censored (for those no longer part of the study due to removal during the observation period). Censoring can occur when athletes are removed due to transfer out of the team/study, injury/illness, or due to study design])
SIIS 9.1: "Data collection methods" SIIS 9.2: "Data collection methods"

)

SIIS 11.1: "Multiple events and health problems" and "Subsequent, recurrent, and/or exacerbation of health problems" SIIS 11.2: "Severity of health problems"

SIIS 12.1: "Capturing and reporting athlete-exposure"

SIIS 12.2: "Expressing risk"

SIIS 12.3: "Burden of health problems"

SIIS 12.4: "Multiple health problems" and "Subsequent, recurrent, and/or exacerbation of injury/illness"

SIIS 12.5: "Capturing and reporting athlete-exposure"

SIIS 12.6: "Capturing and reporting athlete-exposure" 
(continued)

Item

Recommendation From STROBE Statement

Results

(13) Participants ${ }^{b}$

(14) Descriptive data ${ }^{b}$

(15) Outcome data ${ }^{b}$

(a) Report numbers of study (eg, numbers for eligibility, confirmed completing follow-up, and analyzed)

(b) Give the reasons for study participants (eg,

(b) Indicate number of participants with missing data for each variable of interest

(c) Cohort study: summarize and total amount) individuals at each stage of potentially eligible, examined eligible, included in the study, nonparticipation at each stage

(a) Give the characteristics of demographic, clinical, social) and information on exposures and potential confounders follow-up time (eg, average

Cohort study: report numbers of SIIS 15.1: In observational studies, outcome events or summary measures over time

Case-control study: report numbers in each exposure category or summary measures of exposure

Cross-sectional study: report numbers of outcome events or summary measures those with the health problem, and the number of problems reported among them (a median number of problems per affected athlete could be useful)

SIIS 13.2: For studies over multiple seasons/years, report the total number of health problems for each year and number common to each period

SIIS 13.3: Report how athletes who were removed (eg, because of the transfer of teams or timeout due to an injury or illness) impact the data at key data collection/ reporting points, ideally with a flow diagram

SIIS 14.1: Include details on the level of competition being observed (eg, by age level, skill level, sex, etc) individuals will sustain more than one health problem over the surveillance period. Take care to ensure that descriptive data represent both the number of health problems and the number of athletes affected. It is important to represent effectively both the analysis and reporting of correct units for frequency data (ie, the percentage of affected athletes or percentage of injuries, body regions, etc)
Source of Rationale for Item From Consensus Statement and Where to Find Further Details

STROBE-SIIS Extension

SIIS 13.1: Clearly state the number SIIS 13.1: "Multiple health of athletes who were followed up, problems"

the number (and percentage) of SIIS 13.2: "Multiple health problems" and "Expressing risk"

SIIS 13.3: Throughout the consensus statement

SIIS 14.1: "Study population characteristics"
SIIS 15.1: "Multiple health problems" and "Subsequent, recurrent, and/or exacerbation of injury/illness" 
Item

(16) Main results

(17) Other analyses

Discussion

(18) Key results

(19) Limitations

(20) Interpretation

(21) Generalizability

(22) Funding

(23) Ethics

\section{Recommendation From} STROBE Statement

(a) Give unadjusted estimates and, if applicable, confounderadjusted estimates and their precision (eg, 95\% confidence interval). Make clear which confounders were adjusted for and why they were included

(b) Report category boundaries when continuous variables were categorized

(c) If relevant, consider translating estimates of relative risk into absolute risk for a meaningful time period

Report other analyses done (eg, analyses of subgroups and interactions and sensitivity analyses)

Summarize key results with reference to study objectives

Discuss the limitations of the study, taking into account the sources of potential bias or imprecision. Discuss both the direction and magnitude of any potential bias

Give a cautious overall interpretation of results, considering objectives, limitations, multiplicity of analyses, results from similar studies, and other relevant evidence

Discuss the generalizability (external validity) of the study results

Give the source of funding and the role of the funders for the present study and, if applicable, for the original study on which the present article is based
SIIS 17.1: Report injury diagnosis information, including region and tissue type in tabular form
Source of Rationale for Item From Consensus Statement and Where to Find Further Details
SIIS 16.1: Report exposure-adjusted SIIS 16.1: "Expressing risk" incidence or prevalence measures SIIS 16.2: "Relationship to sports with appropriate confidence intervals when presenting risk measures

SIIS 16.2: Report details of interest, such as the mode of onset activity," "Mode of onsetinjury," "Mode of onset-illness," and "Classifying the mechanism of injury"
SIIS 17.1: "Defining and classifying health problems"
SIIS 19.1: Discuss limitations in the data collection and coding procedures adopted, including in relation to any risk measures calculated
SIIS 19.1: "Data collection methods" and "Expressing risk" generalizability of the athlete study population, and health problem subgroups of interest, to broader athlete groups
SIIS 21.1: Discuss the
SIIS 23.1: Outline how individual athlete data privacy and confidentiality considerations were addressed, in line with the Declaration of Helsinki
SIIS 23.1: "Research ethics and data security"
SIIS 21.2: "Relationship to sports activity" and "Study population characteristics" 